\title{
A Leverage Theory of Tying in Two-Sided Markets with Non-Negative Price Constraints*
}

\author{
Jay Pil Choi ${ }^{\dagger} \quad$ Doh-Shin Jeon ${ }^{\ddagger}$
}

October 1, 2019

\begin{abstract}
Motivated by recent antitrust cases in markets with zero-pricing, we develop a leverage theory of tying in two-sided markets. In the presence of the non-negative price constraint, the Chicago school critique of tie-ins fails to hold. In the independent products case, tying provides a mechanism to circumvent the constraint in the tied market without inviting aggressive responses by the rival firm. In the complementary products case, the "price squeeze" mechanism cannot be used to extract surplus from the more efficient rival firm without tying. We identify conditions under which tying in two-sided markets is profitable and explore its welfare implications.
\end{abstract}

JEL Codes: D4, L1, L5

*We thank Bernard Caillaud, Federico Etro, Bruno Jullien, Massimo Motta, Andras Niedermayer, Volker Nocke, James Peck, Martin Peitz, Patrick Rey, Kyoungwon Rhee, Greg Taylor, Chengsi Wang, Huanxing Yang and participants in various conferences and seminars for valuable discussions and comments. We are also grateful to two anonymous referees and Co-Editor John Asker for constructive comments which greatly improved the paper. Taeyoon Hwang and Sungwook Koh provided excellent research assistance. This work was supported by the Ministry of Education of the Republic of Korea and the National Research Foundation of Korea (NRF-2016S1A5A2A01022389). Jeon acknowledges the financial support of the Jean-Jacques Laffont Digital Chair and the funding from ANR under grant ANR-17-EURE-0010 (Investissements d'Avenir program).

${ }^{\dagger}$ Department of Economics, Michigan State University, 220A Marshall-Adams Hall, East Lansing, MI 48824 -1038. E-mail: choijay@msu.edu.

†Toulouse School of Economics, University of Toulouse Capitole. E-mail: dohshin.jeon@gmail.com. 
Key Words: Tying, Leverage of monopoly power, Two-sided markets, Zero pricing, Non-negative pricing constraint 


\section{Introduction}

We develop a leverage theory of tying in two-sided markets. We analyze incentives for a monopolist to tie its monopolized product with products facing competition in two-sided markets. We uncover a new channel through which a monopolistic firm in one market can leverage its monopoly power to another competing market if the latter is two-sided and derive its welfare implications.

Our analysis, motivated by recent antitrust cases in markets with zero-pricing, applies when platforms in a two-sided market are constrained to set non-negative prices on the consumer side. ${ }^{1}$ In two-sided markets the need for all sides of the market to engage creates a "chicken and egg" problem (Caillaud and Jullien, 2003) in that members of each group are willing to participate in the market only if they expect many members from the other side to participate. The literature on two-sided markets has analyzed the optimal pricing structure to coordinate the demands of distinct groups of customers and shows that below-cost pricing naturally arises on one side in order to enhance participation because the loss from the below-cost pricing can be recouped on the other side of the market (see Armstrong (2006) and Rochet and Tirole (2006)). When the marginal cost is low as in digital markets, this implies that the optimal pricing strategy entails negative prices. However, we can imagine situations in which negative prices may be impractical due to adverse selection and opportunistic behaviors by consumers (Farrell and Gallini (1988) and Amelio and Jullien (2012)). ${ }^{2}$

The Chicago school critique of the leverage theory of tying relies on price mechanisms and shows that the monopolist has no incentives to engage in tying to extend its monopoly power to another market. According to the Chicago school, in the independent products case, to induce consumers to buy an inferior tied product through tying, the monopolist needs to compensate them for giving up the opportunity to buy a superior rival product. This requires the monopolist to use part of its monopoly profit from the tying product, which makes tying not a profitable strategy. In the complementary products case, "price squeeze" is a more efficient way of extracting surplus from a more efficient rival firm than monopolizing the tied product market. In the presence of the non-negative price constraint, however, the price mechanisms in the logic of the Chicago school cease to

\footnotetext{
${ }^{1}$ For a discussion of how to apply antiturst law to zero-price markets, including the issues of market definition and market power, from the legal perspective, see Newman $(2015,2016)$.

${ }^{2}$ To quote Farrell and Gallini (1988), "[a]t a negative price, people could take computers at a negative price and use them for landfill (p.679)."
} 
operate. We demonstrate that the two-sidedness of the tied product market in conjunction with the non-negative price constraint provides a new rationale for the leverage theory of tying to appropriate extra revenues generated in the other side of the market.

More specifically, in the case of independent products, we show that tying provides a mechanism to circumvent the non-negative price constraint in the tied product market without inviting an aggressive response by the rival firm if the rival firm's price response to tying faces the non-negative constraint. In our model, the non-negative price constraint plays two roles: 1) it limits competition in the tied good market, which creates additional surplus to extract through tying, and 2) it limits the rival firm's response to tying. To see the incentives to leverage monopoly power, consider a monopolist in one market that also competes in a two-sided market with a more efficient rival firm (i.e., a rival platform). The two-sided market consists of consumers on one side and advertisers on the other. We envision a situation in which consumers are competitive bottleneck in the two-sided market (see Armstrong (2006) and Armstrong and Wright (2007)); a platform can extract extra revenues from the advertiser side when it attracts a consumer from the bottleneck side. First, in the absence of tying, the non-negative price constraint limits competition on the consumer side of the two-sided market and generates additional profit for the more efficient rival firm which cannot be competed away. This creates incentives for the monopolistic firm to tie and effectively engage in a negative price in order to capture this extra surplus. Second, when the monopolistic firm tries to steal the additional profit in the two-sided market, tying will induce a more aggressive response by the rival firm as in Whinston (1990). However, the rival firm's ability to respond aggressively can be muted as the non-negative price constraint begins to bind. Thus, the non-negative price constraint in two-sided markets plays the dual role of creating additional surplus and limiting aggressive response by the rival firm, which provides incentives to tie by the monopolistic firm in the independent products case.

The underlying logic for incentives to tie in the complementary products case differs. It stems from the monopolist's inability to engage in "price squeeze" when the price in the competitive complementary market hits the zero lower bound. As the monopolist cannot fully extract extra revenues available in the two-sided market via price squeeze, tying becomes the only option to capture them. As a result, tying becomes profitable if the extra revenues in the two-sided markets are sufficiently important even though it means giving up the extraction of efficiency gains brought by the rival firm with a price squeeze. 
In addition, our theory fills the gap in the literature by showing that tying is credible without any commitment mechanism and forecloses the rival in the tied product market regardless of whether the two products tied together are independent or complementary. The credibility of tying can explain the use of contractual tying for the leverage purpose. ${ }^{3}$

The paper is motivated by major antitrust investigations in two-sided markets. For instance, the European tying case against Microsoft (IP/04/382) in 2004 concerned Microsoft's tying of its Windows Media Player (WMP) product with its dominant Windows operating system, where the WMP market can be considered as a two-sided market. ${ }^{4}$ The recent antitrust investigations concerning Google in Europe and elsewhere also relate to tying and vertical foreclosure issues in two-sided markets. In one of the investigations, the European Commission (EC) fined Google $€ 4.34$ billion on July 18, 2018 for illegal practices regarding Android mobile devices to strengthen dominance of Google's search engine. ${ }^{5}$ In particular, the EC decision has concluded that Google has engaged in illegal tying by requiring "manufacturers to pre-install the Google search app and browser app (Chrome), as a condition for licensing Google's app store (the Play Store)" which is considered as a "must-have" app, thereby "denying rivals the chance to innovate and compete on the merits." ${ }^{6}$ The tying mechanism we uncover can be applied to the Microsoft WMP and the Google Android cases and can explain why Microsoft and Google have incentives to tie. We further show that such tying arrangements can lead to the exclusion of (more efficient) rival firms, providing a theory of harm associated with Microsoft's WMP tying and Google's practices in the MADA (Mobile Application Distribution Agreement) contracts. $^{7}$

\footnotetext{
${ }^{3}$ The tying literature distinguishes contractual tying from technical tying: the former can be undone ex post with a relatively low cost while the latter can be undone only with a significant cost. Therefore, technical tying can be used as a device to pre-commit to tying when tying is not ex post credible (Whinston, 1990).

${ }^{4}$ We provide more details on this case in section 2.4.1 To the extent that the web browser market is two-sided, our model can also be applied to the Microsoft tying case in the US.

${ }^{5}$ The EC's other abuse of dominance cases on Google concern Google's search engine. Google was fined $€ 2.42$ billion in June 2017 for giving an illegal advantage to Google's own comparison shopping service. See the European Commission Press Release entitled "Antitrust: Commission fines Google $€ 2.42$ billion for abusing dominance as search engine by giving illegal advantage to own comparison shopping service," released on June 27, 2017. Available at http://europa.eu/rapid/press-release_IP-17-1784_en.htm.

${ }^{6}$ See the European Commission Press Release "Antitrust: Commission fines Google $€ 4.34$ billion for illegal practices regarding Android mobile devices to strengthen dominance of Google's search engine," released on July 18, 2018. Available at http://europa.eu/rapid/press-release_IP-18-4581_en.htm. Russian antitrust officials also fined Google $\$ 6.8$ million on August 11, 2016 for abusing its market position with its mobile operating system Android, whereas Google is currently under investigation in Korea and India.

${ }^{7}$ For a detailed discussion of the key aspects of Google's practices and their potentially exclusionary
} 
In section 2, we present our mechanism of tying in the baseline model of homogenous consumers. In a setting in which the well-known "single monopoly profit result" holds if the tied market is one-sided (or in the absence of the non-negative price constraint), we show that the interplay between two-sidedness of the tied market and the non-negative pricing constraint breaks the result and restores an incentive to tie to leverage monopoly power into the tied two-sided market. We consider both the cases of independent and complementary products, respectively in sections 2.1 and 2.2. We then present a theory of harm associated with our leverage theory of tying (section 2.3) where we discuss the conditions under which our theory can be applied. Section 2.4 extends our model to the case where consumers can multi-home. We also briefly discuss how our model can be applied to provide a theory of harm in the Microsoft WMP and the Google shopping cases (section 2.5).

In section 3, we show that our insight is not limited to two-sided markets and can be more widely applied to any markets in which sales to consumers in one market can generate additional revenues that cannot be competed away due to non-negative price constraints. Specifically, even if the tied market is one-sided, additional revenue can be generated in an intertemporal context from the same market in the future in the presence of network effects (section 3.1) or switching costs (section 3.2).

In sections 4 and 5, we extend the baseline model by incorporating heterogenous consumers in the tying market. This allows us to check the robustness of our insight obtained from the baseline model and also addresses the question of how the degree of two-sidedness of the tying market affects the incentive to tie. ${ }^{8}$ Sections 4 and 5 differ in that we introduce intergroup network effects in the tied market in section 5 while no network effect is introduced in section 4 .

More specifically, in section 4 we assume that consumers are bottleneck both in the tying and in the tied two-sided markets. For example, the other side interacting with consumers in both markets could be advertising. In such a case, we find that the incentive to tie increases with the degree of two-sidedness of the tied market but decreases with the degree of two-sidedness of the tying market, where the two-sidedness is represented by the importance of advertising revenues. For instance, when the tying market is sufficiently two-sided while the tied market is close to being one-sided, tying reduces both firms'

effects in the mobile phone industry from a legal perspective, see Edelman and Geradin (2016) and Etro and Caffarra (2017).

${ }^{8}$ In the baseline model of homogenous consumers, the incentive to tie does not depend on the degree of two-sidedness of the tying market. 
profits as in Whinston (1990). Under tying, consumers whose valuations for the monopoly product are low enough prefer buying the competing tied product instead of the bundle. This means that the tying firm loses the advertising revenue in the tying market from these consumers. This loss increases with the degree of two-sidedness of the tying market. As our model in section 4 includes tying in one-sided markets as a special case, it also captures various motives for tying identified by the previous literature in one-sided markets.

Section 5 introduces cross-group network effects in the tied market while maintaining heterogenous consumers in the tying market. For instance, the other side in the tied market could be applications. Consumers' benefits increase with the number of applications and application developers' benefits increase with the number of consumers. When there is no tying, the network effects generate a tipping equilibrium toward the more efficient rival platform in the tied market. However, tying can generate a tipping toward the tying platform and such tipping is more likely as the two-sidedness of the tying market increases. Intuitively, when the tying market becomes more two-sided, the tying platform becomes more aggressive in pricing in order to capture more consumers in the tying market, which generates a larger network effect and hence makes tipping more likely in the tied market. When tipping occurs, there is no loss of advertising revenue in the tying market and therefore the incentive to tie increases with the degree of two-sidedness of the tying market. In addition, we show in Section 5.5 that this insight is valid even if we assume away the non-negativity constraint on pricing. We can apply the model of the inter-group network effects without the non-negative price constraint to the Google Android case because app developers can make payments to original equipment manufacturers (OEMs) to have their apps to be pre-installed, which makes the non-negative price assumption less applicable to OEMs (see section 5.6).

Our paper contributes to the literature on the leverage theory of tying, which has been extensively studied. In a classical paper on tying, Whinston (1990) shows that selling a monopolized primary product and an unrelated differentiated product together as a bundle may allow the monopolist to commit to a more aggressive pricing strategy, preventing entry in the differentiated market. In Carbajo, De Meza, and Seidman (1990), on the other hand, bundling is used as a strategy to segment the market and relax price competition. ${ }^{9}$ By considering a model in which each of the tying and the tied markets can be one-sided or two-sided, our paper encompasses both Whinston's and Carbajo et al.'s results as special cases. In particular, when the tied market is two-sided, we uncover a new

\footnotetext{
${ }^{9}$ See also Chen (1997).
} 
channel through which tying is profitable at the expense of rival firms. We emphasize that our leverage mechanism does not have any credibility issue in sharp contrast to Whinston (1990) and Nalebuff (2004). Our mechanism thus does require neither technical tying as a commitment device as in Whinston (1990) nor the controversial assumption that the tying firm is a Stackelberg leader in setting prices as in Nalebuff (2004). ${ }^{10}$ We show that a monopolist's tying is credible and reduces the rival's profit if the tied market is two-sided, which provides a justification for the use of contractual tying. We further show that tying is credible and forecloses the rival even in the case of perfect complements. This result is noteworthy because it is known that a monopolist selling a perfectly complementary product has no incentive to practice tying to exclude the rival (Proposition 3 of Whinston, 1990).

Carlton and Waldman (2002, 2012) and Choi and Stefanadis (2001) provide a dynamic leverage theory of tying. In particular, Carlton and Waldman (2012) develop a model where imperfect rent extraction motivates incentives to tie. More specifically, they consider a two-period model in which an upgrading opportunity for the secondary complementary product arises in the future. In their set-up, future rents from upgrading cannot be captured by the monopolist of the durable primary complementary product when it is sold in the first period. This inability to extract these rents through "price squeeze" in the current period induces the monopolist to engage in tying. As discussed in section 3 , future rents from upgrading opportunities in their model can be considered another instance of ancillary revenues that cannot be competed away in the tied good market. ${ }^{11}$ We show how the two-sidedness of markets in conjunction with the non-negative price constraint generates a new channel through which monopoly power in one market can be leveraged into another. ${ }^{12}$

\footnotetext{
${ }^{10} \mathrm{~A}$ notable exception is Peitz (2008), who points out the credibility issue and builds an example in which a monopolist's tying is credible and reduces the rival's profit. Hurkens, Jeon and Menicucci (forthcoming) restores credibility by considering that the tying firm is not a monopolist but a dominant firm facing competition in the tying market. In the context of competition among product portfolios in a common agency setting, Jeon and Menicucci $(2006,2012)$ find that pure bundling is credible as it reduces competition among the products within a firm's portfolio but that competitive bundling leads to efficient outcome if the buyer has no budget constraint (otherwise, bundling builds an entry barrier since it allows firms with large portfolios to capture all the budget).

${ }^{11}$ We further discuss the relationship between our paper and Carlton and Waldman (2012) in section 2.2 .

${ }^{12}$ Choi and Stefanadis (2001) and Carlton and Waldman (2002) construct leverage models of tying in which success of entry in one market is linked to the success of entry in another market. In the case of complementary products, entry deterrence in the competitive market via tying entails short-run losses by forsaking the opportunity to squeeze rents from more efficient rival firms. However, it can generate
} 
Amelio and Jullien (2012) analyze the effects of tying in two-sided markets. They consider a situation in which platforms would like to set prices below zero on one side of the market to solve the demand coordination problem in two-sided markets, but are constrained to set non-negative prices. In the analysis of Amelio and Jullien, tying can serve as a mechanism to introduce implicit subsidies on one side of the market in order to solve the aforementioned coordination failure in two-sided markets. As a result, tying can raise participation on both sides and can benefit consumers in the case of a monopoly platform. In a duopoly context, however, tying also has a strategic effect on competition. They show that the effects of tying on consumer surplus and social welfare depend on the extent of asymmetry in externalities between the two sides. Their paper and ours are very different in terms of focus and mechanisms through which tying affects competition. Their main focus is to compare the effects of tying across different market structures (monopolistic vs. duopolistic) whereas our focus is on the leverage of monopoly power in two-sided markets. Choi (2010) and de Cornière and Taylor (2017) also analyze tying in two-sided markets. The main focus in Choi (2010) is on the role of multi-homing on both sides of the market. In particular, he shows that tying can be welfare-enhancing if multi-homing is allowed, even in cases where its welfare impacts are negative in the absence of multi-homing. Motivated by the Google Android case, de Cornière and Taylor (2017) study a setting in which application developers compete to have their applications installed on devices. They show how bundling lowers the device manufacturer's outside option and allows a multi-application developer to extract more surplus when applications are a main driver of consumer demand.

Finally, Iacobucci (2014) develops a similar idea to our mechanism. ${ }^{13}$ In particular, he argues that the elimination of competition, via tying of two platforms, in one side of the market can expand the set of customers to whom the tying platform can sell in the other side of the market. This is similar to our mechanism in which capturing the customer side provides additional revenue from the advertiser side. However, he does not provide a formal analysis as his argument is based on a numerical example. In addition, his logic breaks down when the non-negative price constraint is not binding as the same effects can be achieved by an appropriate pricing scheme without the use of tying. This is due to his implicit assumption that without tying, platforms in the tied product market set price equal to marginal cost on each side in a competitive equilibrium. However, this does not

long term gains by preventing potential future entry into the monopolized market.

${ }^{13}$ See also Iacobucci and Ducci (2019). 
need to hold as zero profit condition for the platforms requires only the total price to be equal to the total marginal cost. In contrast, we provide a rigorous and formal analysis of tying that fully accounts for intricacies of two-sided markets.

The rest of the paper is organized in the following way. In section 2 , we present the baseline model of homogenous consumers to highlight the main essence of the leverage mechanism in two-sided markets and the importance of the non-negative price constraint. We also establish the robustness of our mechanism to multihoming and discuss the Microsoft Windows Media and the Google shopping cases in light of our model. In section 3 , we demonstrate the applicability of our framework to other types of markets with auxiliary revenues. In section 4, we extend the baseline model by introducing heterogenous consumers in the tying market and investigate how the two-sidedness of both the tying and tied product markets interact to draw policy implications. In section 5, we consider a model with inter-group network effects in the tied good market. We provide concluding remarks in section 6. Detailed proofs are relegated to the Appendix.

\section{The Leverage Mechanism with the Non-Negative Price Con- straint in Two-Sided Markets}

To show how the interaction between the two-sidedness of markets and the non-negative price constraint generates new incentives to tie, we start by analyzing a simple baseline model of homogenous consumers. In order to highlight the leverage mechanism in twosided markets, we consider a setting in which the well-known "single monopoly profit" result holds and hence the extension of monopoly power from one market to another is not possible in the benchmark without two-sided markets.

Consider two markets, $A$ and $B$. We build a simple framework to analyze tying as a leverage mechanism when both markets are characterized as two-sided. More specifically, in each market there are three classes of agents: two distinct customer groups (consumers and advertisers) that interact with each other and intermediaries which enable these two groups to "meet" with each other. In the example of the Internet search market, the two customer groups can be described as advertisers and consumers (who search for information through the Internet). The intermediaries are search engine providers such as Google and Bing.

To analyze incentives to leverage market power, we assume that market $A$ is served by firm 1, a monopolistic platform, and entry to market $A$ is not possible. In contrast, two 
platforms, firm 1 and firm 2, compete in market $B$. More specifically, we envision a competitive bottleneck situation in which platforms sell products (for instance, applications) to consumers and use the customer base to derive advertising revenues from advertisers who need access to consumers. There is a mass one of identical consumers, who have a unit demand for each product. To focus on the strategic motive for bundling, we assume that there is no cost advantage or disadvantage associated with bundling.

The relationship between the product in market $A$ and a product in market $B$ can be either independent or complementary. The two products are independent when the value that a consumer obtains from a product does not depend on whether a consumer consumes or not the other product. We present these two cases separately because the underlying logic for incentives to tie differs across the two cases.

\subsection{Tying in Independent Products Case}

We first consider the case where products $A$ and $B$ are independent and can be used separately. In market $A$, each consumer's reservation value is denoted by $u>0$. In market $B$, each consumer's willingness to pay for each firm's product is given by $v_{1}>0$ and $v_{2}>0$, respectively, where $\Delta \equiv v_{2}-v_{1}>0 .{ }^{14}$ For most of the paper, we assume that each consumer buys only one of the two products in market $B$ and normalize firms' production costs to zero in all markets. Note that this is not an innocuous normalization assumption with the non-negative price constraint because it also implies no below-cost pricing. However, as long as production costs are not too high (as would be the case for digital goods), our results would be robust even if we allow below-cost pricing (see the Appendix for details). More importantly, we can derive qualitatively similar results when we introduce asymmetry between the two firms in market $B$ in terms of production costs rather than product qualities. This single-homing assumption is relaxed in section 2.4. Each consumer yields additional profit of $\alpha \geq 0$ and $\beta \geq 0$ to the advertiser side in market $A$ and $B$, respectively. ${ }^{15}$ If $\alpha=0$, the tying market is one-sided and if $\beta=0$, the tied market is one-sided.

Consider the benchmark in which both markets are one-sided (i.e., $\alpha=\beta=0$ ). If these products are sold independently without tying, firm 1 will charge $p_{1}^{A}=u$ in its

\footnotetext{
${ }^{14}$ This is a standard assumption in the leverage theory of tying to analyze potential exclusion of more efficient rival firms. This assumption is made to facilitate comparison with the prior literature, and should not be taken to imply that Google products are inferior to rival firms'.

${ }^{15}$ Alternatively, $\alpha$ and $\beta$ can represent additional revenues coming from sale of consumer data to third parties or in-app purchases. See de Cornière and Taylor (2017).
} 
monopolized market $A$. In market $B$, both firms compete in prices and the equilibrium prices are given by $p_{1}^{B}=0$ and $p_{2}^{B}=\Delta$. All consumers buy from firm 2. Each firm's profits are given by

$$
\begin{aligned}
& \Pi_{1}=\pi_{1}^{A}+\pi_{1}^{B}=u+0=u \\
& \pi_{2}^{B}=\Delta .
\end{aligned}
$$

Now suppose that firm 1 ties its monopolized product $A$ with product $B 1$. Let $\widetilde{P}$ and $\widetilde{p}_{2}$ denote the bundle price and firm 2 's price for product $B$ under tying. ${ }^{16}$ We assume that a consumer buys either the $(A, B 1)$ bundle or product $B 2$ : this assumption is relaxed by allowing multi-homing in section 2.4. Then, firm 1 will be able to sell its bundled products only if

$$
u+v_{1}-\widetilde{P} \geq v_{2}-\widetilde{p}_{2}
$$

Since firm 2 will be willing to set the price as low as its marginal cost, which is zero, the maximum price firm 1 can charge for its bundle in order to make sales is given by $\widetilde{P}=u-\Delta$. Under tying, firm 1's profit is given by

$$
\widetilde{\Pi}_{1}=\max [u-\Delta, 0]
$$

which is less than the profit without tying as $\widetilde{\Pi}_{1}=\max [u-\Delta, 0]<u=\Pi_{1} \cdot{ }^{17}$ Thus, even if tying provides a mechanism to capture the tied good market, it is a Pyrrhic victory as it reduces firm 1's profits. Thus, the monopoly firm has no incentives to tie to extend its market power to the other market. This is the essence of the Chicago school's criticism of the leverage theory of tying. However, this conclusion can be overturned if the tied good market $B$ is two-sided.

Suppose now that market $B$ is two-sided while market $A$ is one-sided. Assume that the advertising revenue is large enough in market $B$ such that $\beta>\Delta$ holds. ${ }^{18}$ Due to this additional revenue source, now each firm in market $B$ is willing to set its price below its marginal cost on the consumer side up to $\beta$. We, however, put a non-negative price restriction that the market prices cannot be negative. ${ }^{19}$ Thus, in the absence of tying,

\footnotetext{
${ }^{16}$ We denote variables under the tying regime with a tilde $(\sim)$.

${ }^{17}$ If $v_{1} \geq v_{2}$, firm 1's profit with tying is the same as the one without tying.

${ }^{18}$ According to the estimates by financial analyst Richard Windsor, Google made about $\$ 11$ billion in 2015 from advertising sales on Android phones through its apps such as Maps, Search and Gmail. See Chee (2016).

${ }^{19}$ We discuss about the plausibility of this constraint in more detail in section 2.3 .
} 
once again firm 1 charges a price of $p_{1}^{B}=0$ and firm 2 will set the price of $p_{2}^{B}=\Delta$. Firm 1 's profit in market $B$ is zero. However, note that firm 2' profit is given by $\pi_{2}^{B}=\Delta+\beta$ due to the additional revenue from the advertiser side.

Now suppose that firm 1 ties its monopolized product with product $B$ on the consumer side. Assume $u>\Delta$ such that firm 1 can conquer market $B$ by tying. Once again, the maximum bundle price that enables the tying firm to make sales is given by $\widetilde{P}=u-\Delta$. However, due to the additional revenue source in market $B$, the tying firm's profit now becomes $\widetilde{\Pi}_{1}=u+(\beta-\Delta)>u=\Pi_{1}$. Hence, tying is profitable if the tied good market is two-sided.

Tying reduces welfare because it induces consumers to use the inferior product of firm 1. However, consumers benefit from tying due to reduced prices. Consumer surplus without tying can be expressed as $C S=\left(u+v_{2}\right)-(u+\Delta)=v_{1}$. With tying, consumer surplus is $\widetilde{C S}=\left(u+v_{1}\right)-(u-\Delta)=v_{1}+\Delta=v_{2}\left(>v_{1}=C S\right)$.

This simple model also illustrates the importance of the non-negative price constraint for the two-sidedness of the market to restore incentives to tie. ${ }^{20}$ To see this, suppose that firms can charge a negative price. Then, after tying firm 2 would be willing to set the price as low as $-\beta$. Thus, the maximum bundle price that enables the tying firm to make sales is now given by $\widetilde{P}=u-\Delta-\beta$. As a result, the tying firm's profits is now reduced to $\widetilde{\Pi}_{1}=u-\Delta<u=\Pi_{1}$ as in the Chicago school benchmark case above.

We can also consider the case in which the tying market is two-sided (i.e., $\alpha>0$ ). This would increase firm 1's profit by $\alpha$ regardless of tying as long as it sells its monopoly product. Hence, whether the tying market is one-sided or two-sided does not affect the incentive to tie.

Summarizing, we have:

Proposition 1. Consider the baseline model of homogenous consumers in which products have independent values.

(i) Tying is never profitable and hence the single monopoly profit result holds either if the tied-market is one-sided or if firms can charge negative prices.

(ii) Suppose $u>\Delta$. Tying is profitable if the tied-market is two-sided such that $\beta>\Delta$ holds and firms cannot charge negative prices. Then, tying reduces both firm 2's profit and social welfare, but increases consumer surplus.

\footnotetext{
${ }^{20}$ Our leverage theory can also be applied to other kinds of price restrictions such as price regulations that prohibt a price below a certain level.
} 
(iii) Whether the tying market is one-sided or two-sided does not affect the above results.

Our simple model demonstrates two important differences between the case of a onesided tied product and that of a two-sided tied product, both of which are generated by the non-negative price constraint. First, in the absence of tying, firm 2 realizes a profit beyond its competitive advantage: its profit per consumer is larger than $\Delta$ by $\beta$, which cannot be competed away due to the binding non-negative price constraint that firm 1 faces. This creates an incentive for firm 1 to practice tying in order to subsidize its product $B$ by circumventing the constraint of non-negative pricing. Second, when firm 1 practices tying and is effectively engaging in negative pricing for the tied product, firm 2 would respond more aggressively against tying. However, its aggressive response can be limited as firm 2 hits the zero price floor even though it is willing to set a price as low as $-\beta$. Therefore, tying in two-sided markets can be immune to an aggressive price response by the rival firm because the non-negative price constraint limits an aggressive response. ${ }^{21}$

Tying reduces welfare as it induces consumers to consume the inferior product of firm 1 instead of the superior product of firm 2 in market $B$. This force will be preserved in any extension. However, tying may increase welfare by expanding the sale of the monopoly product, which we examine in a model of heterogenous consumers in market $A$ in sections 4 and 5 .

Two remarks are in order. First, the result in Proposition 1(ii) that tying increases consumer surplus has to do with the fact that tying reduces firm 2's price from $\Delta$ to zero and results from the assumption of homogenous consumers. Instead, if consumers are heterogenous in terms of their valuations of firm 2's product, then firm 2 may find it optimal to charge a zero price in the absence of tying because of the advertising revenue. In this case, tying will not affect the price charged by firm 2 and hence will not increase consumer surplus. Second, for a similar reason, Proposition 1(iii) is likely to be an artifact of the assumption of homogenous consumers. In order to investigate how the degree of two-sidedness in the tying market (captured by $\alpha$ ) affects firm 1's incentive to tie, we consider heterogenous consumers in the tying market in sections 4 and 5 .

\footnotetext{
${ }^{21}$ In the actual Google case, competition in search engines takes place mainly with payments to OEMs for pre-installation of the applications (not to consumers), which can be at odds with our assumption of non-negative pricing. We address this issue in section 2.4.2.
} 


\subsection{Tying in Complementary Products Case}

In this section, we show that the leverage mechanism can also be applied when the tying and the tied products are complements. The underlying logic and the roles of the non-negative price constraint in the leverage mechanism, however, are different from the independent products case. This extension is important because most antitrust cases in tying entails complementary products, including the Microsoft Windows Media Player case which motivated our study. The complementary product case can also justify our implicit assumption that only the monopoly firm is able to use tying as a mechanism to engage in negative pricing for the tied product.

Suppose that the monopoly product $A$ of firm 1 and product $B$ are perfect complements that need to be used together. Consumers can use one of the two system products, $(A, B 1)$ and $(A, B 2)$, depending on which firm's product $B$ is used. Consumers' valuation for system $(A, B i)$ is given by $u+v_{i}$, where $i=1,2$ and $\Delta \equiv v_{2}-v_{1}>0$. Once again, we demonstrate that the non-negative price constraint (in conjunction with the two-sidedness of the tied good market) can create incentives to tie even for the perfect complements case. Assume $\alpha=0 .{ }^{22}$

As a benchmark, consider first the case in which the non-negative price constraint is not binding. Without tying, firms are willing to cut the price down to $-\beta$ for product $B$ and firm 2's profit can never be larger than $\Delta$. In fact, there is a continuum of Nash equilibria due to firm 1's ability to "price squeeze" and extract a portion of the surplus $\Delta$ (Choi and Stefanadis, 2001). More precisely, there is a continuum of equilibria parameterized by $\lambda \in[0,1]$, which represents the degree of price squeeze exercised by firm 1 :

$$
\widehat{p}_{1}^{A}=u+v_{1}+\beta+\lambda \Delta, \widehat{p}_{1}^{B}=-\beta-\lambda \Delta, \widehat{p}_{2}^{B}=-\beta+(1-\lambda) \Delta
$$

In equilibrium, consumers purchase the system that includes $B 2 .^{23}$ Firm 1 's profit is $\Pi_{1}=\widehat{p}_{1}^{A}=u+v_{1}+\beta+\lambda \Delta$ and firm 2's profit is $\pi_{2}=\widehat{p}_{2}^{B}+\beta=(1-\lambda) \Delta$. It can be easily verified that no firm has an incentive to deviate because they jointly extract the full surplus from consumers.

With tying, only system $(A, B 1)$ is available to consumers since products $A$ and $B$ are

\footnotetext{
${ }^{22} \mathrm{As}$ in the analysis of products having independent values, adding $\alpha>0$ does not affect the analysis.

${ }^{23}$ We adopt the standard tie-breaking convention that if a consumer is indifferent between buying product $B$ from firms 1 and 2 , he will buy from firm 2 (the high-quality product producer) because this convention is equivalent to defining price equilibrium as the limit in which prices must be named in some discrete unit of account of size $\epsilon$ as $\epsilon \rightarrow 0$.
} 
perfect complements. Firm 1's profit under tying is $\widetilde{\Pi}_{1}=u+v_{1}+\beta\left(<\Pi_{1}\right)$ while firm 2 's profit is zero. Therefore, for any $\lambda \in[0,1]$, firm 1 has no incentive to practice tying to exclude the superior complementary product of the rival firm. This result reconfirm's Whinston 's (1990) finding (i.e., Proposition 3, p.851) and lends support to the Chicago school's criticism of the leverage theory. ${ }^{24}$

Consider now the case in which the non-negative price constraint is binding. Without tying, once again, we have a continuum of equilibria parameterized by $\lambda \in[0,1]$ :

$$
p_{1}^{A}=u+v_{1}+\lambda \Delta, p_{1}^{B}=0, p_{2}^{B}=(1-\lambda) \Delta .
$$

The non-negativity constraint binds for firm 1's product $B$ (i.e., $p_{1}^{B}=0$ ). As a result, consumers prefer buying $B 2$ at any price $p_{2}^{B}$ smaller than $\Delta$. This means that firm 2 captures the advertising revenue $\beta$ while firm 1 can extract $\lambda \in[0,1]$ fraction of $\Delta$ from firm 2. Hence, each firm's profit without tying is given by:

$$
\Pi_{1}=u+v_{1}+\lambda \Delta, \pi_{2}=p_{2}^{B}+\beta=(1-\lambda) \Delta+\beta .
$$

With tying, firm 1 can charge $\widetilde{P}=u+v_{1}$ and receives a profit of $\widetilde{\Pi}_{1}=\widetilde{P}+\beta=u+v_{1}+\beta$ and firm 2's profit is zero. Hence, as long as $\beta>\Delta$, firm 1 has an incentive to tie regardless of the value of $\lambda$.

Summarizing, we have:

Proposition 2. Consider the baseline model of homogenous consumers in which products are perfect complements.

(i) If firms can charge negative prices, tying is never profitable regardless of whether the tied-market is one-sided or two-sided.

(ii) If firms cannot charge negative prices and the tied-market is two-sided enough (i.e., $\beta>\Delta$ ), tying is profitable regardless of the degree of price squeeze prevailing in the absence of tying.

In the case of perfect complements, our mechanism for leveraging monopoly power through tying is to some extent akin to Carlton and Waldman (2012). They consider the standard set-up in which a monopolist for the primary product faces a more efficient rival

\footnotetext{
${ }^{24}$ For instance, according to Posner (1976, p. 173), "[A fatal] weakness of the leverage theory is its inability to explain why a firm with a monopoly of one product would want to monopolize complementary products as well. It may seem obvious ... but since the products are by hypothesis used in conjunction with one another ... it is not obvious at all."
} 
firm in the complementary market. The novelty in their model is that they consider a two period model with durable products, but firms can invest to upgrade the complementary product in the second period. The investment generates additional rents, which creates the monopolist's incentive to engage in tying so as to appropriate those rents. The key assumption in Carlton and Waldman (2012) is that the price that the monopolist can set for the primary product in the first period cannot be contingent on the future availability of upgrades. As a result, the monopolist cannot let the more efficient rival sell the complementary product, engage in the investment and then appropriate the additional rents through the price of the primary product. The only way for the monopolist to appropriate the additional rents is to sell both the primary and complementary products in the first period and to undertake the investment in the second period. Tying provides such a mechanism. Thus, in their model, the additional rents from upgrade in the second period plays the role of $\beta$ in our model.

However, as shown in section 2.1, our mechanism also works for the case of independent products. In this respect, it is worthwhile to emphasize the different roles played by the non-negativity price constraint in the leverage mechanism across independent and complementary products. In the case of independent products, the non-negativity price constraint plays the dual role of creating a rent to steal prior to tying and muting the aggressive response of the rival after tying. In the case of complementary products, the non-negative price constraint limits the monopolist's ability to engage in price squeeze without tying, which creates incentives to tie. Note that in the complementary case, after tying, the rival firm simply cannot compete in the market and is simply unable to put any competitive pressure in terms of prices. Thus, after tying the non-negative price constraint is not relevant.

Our theory also exposes the flaw in the reasoning of Iacobucci (2014) who proposes a theory of tying for perfect complements in two-sided markets: the two-sidedness is a necessary condition for tying to be credible, but not a sufficient condition because it should be combined with the non-negativity constraint in pricing as we have shown above.

\subsection{A Theory of Harm with Tying}

Based on the theory we develop in sections 2.1 and 2.2 (for the independent and complementary products cases, respectively), we comment on the implications of such theory for competition policy and the features that an industry must exhibit for such tying theory of harm to be applied. Note that the Chicago school critique of the leverage theory of 
tying hinges on price mechanisms and argues that the monopolist has no incentives to engage in tying to extend its monopoly power to another market. More specifically, in the independent products case, forcing consumers to buy an inferior tied product through tying requires the monopolist to use part of the monopoly profit from the tying product to compensate consumers for relinquishing the option to buy a superior rival product and thus is not a profitable strategy. In the complementary case, "price squeeze" is a more efficient way of extracting surplus from a more efficient rival firm than monopolizing the tied product market. Our theory essentially demonstrates that once the non-negative price constraint is binding, there is no price channel through which the Chicago school type argument operates. The two-sidedness of the tied product market in conjunction with the non-negative price constraint provides a new rationale for the leverage theory of tying to appropriate extra revenues generated in the other side of the market.

In what follows, we provide a theory of harm covering both the independent and complementary products cases. As the non-negative constraint is essential to our theory of harm, we first discuss the circumstances under which the constraint is reasonable. Second, even when the constraint is binding, our theory of harm may require other conditions to be met depending on whether the products are independent or complementary. We also discuss these additional conditions.

Let us first consider the circumstances under which the non-negativity price constraint is reasonable and the extent to which this assumption can be relaxed. In our theory, there exist extra revenues (represented by $\beta$ ) that are generated with the consumption of product $B$ (the tied product), which motivates the negative price. A negative price, however, may induce consumers to artificially inflate their demands just to receive a subsidy, leading to infinite demands. The plausibility of the constraint thus crucially depends on whether or not adverse selection and moral hazard in the form of artificial (over-)consumption by consumers can be monitored. More specifically, if there is a oneto-one linkage between the demand of the product and extra revenues (i.e., all demands directly translate to extra revenues), there would be no problem with the negative price, which makes the non-negative price constraint less plausible. This would be the case if platforms can make a negative price (i.e., the payment of a gift) conditional on the consumer generating surplus to the other side. ${ }^{25}$ The problem arises (and the constraint is binding) when the mere fact that consumers demand the product does not necessarily

\footnotetext{
${ }^{25}$ See Armstrong and Wright (2007) and Carlton and Waldman (2012) for related discussions on the feasibility of negative prices.
} 
imply that extra revenues are generated.

As examples to make the point, compare the cases of the credit cards vs. Google search. In the credit card industry, for instance, every time a customer uses her/his credit card extra revenues are generated in the form of interchange fees for the issuing bank, whereas cashback reward programs that offer rebates on card holders' purchases can be considered as a negative price. In the example of the credit card, the cashback rewards are directly linked to the credit card usage that generates extra revenues. That is, the negative price is conditional on the generation of extra-revenues by the (real) use of the product. As a result, there is a built-in monitoring mechanism to prevent consumers' moral hazard and abuse of the program. Thus, a negative price can be implemented in the credit card industry. By contrast, in the case of search engines the constraint can be strictly binding. To see this, suppose that Google pays a small amount of money to anyone performing a Google search. There would be consumers who do random Google searches all day just to collect money, or people could create a software program that does automated search on their behalf. If consumers engage in random search, they would not pay attention to what they are searching for and extra-revenues from advertisers would not be realized. Such behaviors would undermine Google's business model, because the only reason advertisers pay money to Google is for targeted advertising tailored to those who do real searches. The same logic applies if we interpret $\beta$ as revenues from in-app purchases. The app producers can generate $\beta$ only from consumers who actually use the program. With a zero or negative price, there can be consumers who receive free items or free money from the app but never actually use it and thus do not make any in-app purchases.

Beyond the non-negative price constraint discussed above, in the independent products case we need two additional conditions for a theory of harm associated with tying in our model. First, tying should be an effective way to circumvent the non-negative price constraint and engage in negative pricing, as in Amelio and Jullien (2012). For this condition to be satisfied, the two products included in the bundle need to have a common user base. In our leverage mechanism tying provides implicit subsidies by conditioning a negative price to the tied product on purchasing the tying product. However, if the consumers of the tied product simply have no demand for the tying product, the mechanism fails to work as they are not willing to pay for the tying product in the first place. Similarly, if the consumers of the tying product have no demand for the tied product, tying in our mechanism would just offer an unnecessary discount to the consumers of the tying 
product without generating any extra revenues in the tied product market. ${ }^{26}$ Second, the rival firm should not be able to engage in its own tying arrangement with another product (say, product $C$ ) as a counter-strategy to circumvent the non-negative price constraint.

Note that the two additional requirements for our theory of harm in the independent products case are irrelevant for the complementary products as they are automatically satisfied. Because the two products in the bundle are always used together for complements, the consumer base is identical. Tying simply eliminates the rival product from competition and hence only the bundle of the tying firm is consumed. In addition, if product $A$ is an essential product for the use of $B$ and monopolized by the tying firm, a counter-strategy via its own tying is simply not available to the rival firm. This may explain why most tying cases entail complementary products.

For the independent products case, the second requirement would imply that the rival firm lacks an alternative product $C$ that would share the same user base of product $B$. To formalize this idea for the independent products case, let us introduce another good $C$ with a value of $w$ in the model, which can be tied with product $B$ by firm 2 as a counter-strategy. In addition, we modify the model with additional number of consumers (with a measure of $\mu$ ) who value only product $C$ (i.e., have no value for products $A$ and $B)$ which is competitively supplied at the marginal cost of $c(<w) .{ }^{27}$ In this case, we ask whether firm 2 can use tying of product $B$ and $C$ as a way to provide a subsidy for product $B$. We can easily verify that the lowest bundle price firm 2 can offer for the bundle consisting of $B$ and $C$ would be $\max \left[c-\frac{\beta}{1+\mu}, 0\right]$, thus effectively providing a subsidy of $\min \left[\frac{\beta}{1+\mu}, c\right]$ to the consumer, which induces a negative price of $\widetilde{p}_{2}=-\min \left[\frac{\beta}{1+\mu}, c\right]$. Given this, the tying firm needs to price its own bundle at the price of $\widetilde{P}=u-\Delta-\min \left[\frac{\beta}{1+\mu}, c\right]$ to limit firm 2's counter-strategy, with the profit of $\widetilde{\Pi}_{1}=u-\Delta+\max \left[\frac{\mu}{1+\mu} \beta, \beta-c\right]$. Thus, if $\beta>\Delta+\min \left[\frac{\Delta}{\mu}, c\right]$, that is, $\mu$ is sufficiently large or $c$ is sufficiently small, tying by firm 1 is still profitable and firm 2's own tying cannot be an effective counter-strategy to engage in negative pricing. This simple analysis formalizes that our leverage mechanism via tying is more applicable when the demands for the tying and the tied products are

\footnotetext{
${ }^{26}$ In addition, for this disguised negative pricing via tying not to invite the same moral hazard problem associated with negative pricing, it is also necessary that marginal utility of the tying product decreases. This would be certainly the case for the unit demand assumed in our model. Otherwise, consumers could buy infinite units of the bundle once again to take advantage of the implicit subsidy.

${ }^{27}$ As for products $A$ and $B$, we can also consider $C$ as a digital good with marginal cost of zero. In this case, $C$ cannot be competitively supplied to be used as a subsidy mechanism because including a freely available good does not provide any benefits to consumers. However, if firm 2 is a monopolistic supplier of $C$, the same analysis that follows applies with the variable $c$ being replaced by $w$.
} 
closely related in the independent products case so that an implicit subsidy can be better targeted, and the marginal costs are relatively small.

As discussed above, the root of the problem with a strictly negative price is the inability to monitor consumers' moral hazard to maximize their net benefits by purchasing multiple units or adverse selection by consumers with no genuine demand for the product. In this regard, the non-negative price constraint is less relevant when buyers are firms as opposed to final consumers because monitoring is easier for firms. ${ }^{28}$

\subsection{Extension to Multihoming}

Up to now, we have assumed that multihoming is impossible. We here allow consumers to multihome at some cost. We analyze both the independent and complementary products cases. The multihoming cost may be due to the limited screen space, limited storage space, or purely psychological default bias. Let $m$ denote the multihoming cost. Consumers are heterogenous in terms of the multihoming cost, which is assumed to be distributed over $[0, \bar{m}]$ according to distribution $G($.$) with strictly positive density g($.$) , where \bar{m}=\infty$ is allowed. In addition, assume that the distribution function $G($.$) is log-concave and$

$$
\bar{m}>\Delta, G(\Delta) / g(\Delta) \leq \beta
$$

With a log-concave density function, $G(.) / g($.) is increasing. Thus, $G(\Delta) / g(\Delta) \leq \beta$ means that the revenue from the advertising side is large enough in market $B$ compared to the degree of superiority of firm 2's product $\Delta$.

Consider first the independent products case. Note that the introduction of multihoming does not affect the analysis of no tying as there is no multihoming. We extend the tying analysis of Section 2.1. Consider $\alpha=0$ and $\beta>0 .{ }^{29}$ Our analysis shows that the equilibrium prices with multi-homing are the same as those in the previous analysis where multihoming is not feasible. We thus have the following proposition.

Proposition 3. Consider the baseline model of homogenous consumers in which products have independent values. Suppose that multi-homing is possible.

\footnotetext{
${ }^{28}$ For instance, the assumption of non-negative prices is not appropriate in the Google Android case since app developers can make payments to OEMs to have their apps to be pre-installed. In section 5.5, we show how the assumption of the non-negative prices can be dispensed with in a model with network effects.

${ }^{29}$ Analyzing the case of $\alpha>0$ does not affect the result because firm 1 's profit increases by the same amount of $\alpha$ with or without tying.
} 
(i) Without tying, all consumers use the superior product of firm 2 in market $B$ and no consumers multi-home.

(ii) With tying, the equilibrium prices are given by $\widetilde{P}=u-\Delta$ and $\widetilde{p}_{2}=0$. Consumers whose multi-homing cost is less than $\Delta$ multi-home. Tying is profitable if $\beta>\frac{\Delta}{[1-G(\Delta)]}$, that is, $\beta$ is relatively large compared to $\Delta$. Social welfare always decreases with tying even though consumers are better off.

Proof. See the Appendix.

Introducing multihoming does not affect the equilibrium prices and those whose multihoming cost is above $\Delta$ singlehome and buy only the bundle (while all the others multihome and consume the rival product). Therefore, Proposition 3(ii) naturally generalizes Proposition 1(ii) in that the tying firm obtains $\beta$ from $[1-G(\Delta)]$ measure of singlehoming consumers whereas it reduces the price of the tying good by $\Delta$ to all consumers; when all consumers singlehome, $1-G(\Delta)$ is simply equal to one as in Proposition1(ii). This implies that multihoming makes tying less profitable compared to singlehoming. The more consumers multihome (i.e., the higher the probability of $G(\Delta)$ ), the more stringent the condition for profitable tying. In the extreme case in which all consumers multihome, tying is never profitable.

Tying reduces welfare because single-homing consumers use the inferior tied product while those who multihome incur the cost of multihoming. However, tying increases every consumer's surplus at the expense of firm 2, as firm 2 charges a zero price and captures a smaller market share. More precisely, in the absence of tying each consumer has a surplus of $v_{1}$. Under tying with multi-homing, a consumer receives a surplus of $v_{1}+$ $\Delta+\max [0, \Delta-m]$. Firm 2's profits decrease from $(\Delta+\beta)$ to $G(\Delta) \beta$.

We can also perform the analysis of multihoming for the complementary products case. As in the case of the independent products case, the analysis of no tying is not affected since no consumer multihomes. In the case of tying, we should distinguish two scenarios depending on whether or not tying is achieved by making the tying product incompatible with product B2. If tying is achieved by incompatibility, then the previous analysis is not affected as there is no point of buying two incompatible products. If tying is done without affecting compatibility, then we can show that $\widetilde{P}=u+v_{1}$ and $\widetilde{p}_{2}=0$ is an equilibrium under an additional assumption that $u+v_{1}>\beta .{ }^{30}$ Hence, firm 1's profit under tying

\footnotetext{
${ }^{30}$ The proof is similar to the proof of the independent products case. The analysis of the deviation by firm 2 is identical. In the case of the deviation of firm 1, it is straightforward to show that firm 1 has no
} 
is given by $u+v_{1}+[1-G(\Delta)] \beta$ whereas the profit under singlehoming is $u+v_{1}+\beta$. Therefore, multihoming makes tying less profitable as in the independent products case.

In the rest of the paper, we maintain the single-homing assumption.

\subsection{Applications to the Microsoft Windows Media Player and the Google Shopping Cases}

We have developed a leverage theory of tying in two-sided markets with the non-negative price constraint in the tied good market. We briefly discuss how our model (or a variation of it) can be applied to the Microsoft Windows Media Player and the Google shopping cases.

\subsubsection{The Microsoft Windows Media Player Case}

One of the major European antitrust cases concerned Microsoft's tying of its Windows Media Player (WMP) product with its dominant Windows operating system. The European Commission concluded that this tying arrangement "deprived PC manufacturers and final users of a free choice over which products they want to have on their PCs," thereby violating the EU Treaty's competition rules (Article 82 ). ${ }^{31}$ A theory of harm in this case is different from Microsoft's bundling of Internet Explorer in Windows because in the browser case a successful rival browser has the potential to evolve into a substitute for Windows whereas a rival media player is not considered as such a threat.

The Commission's decision was mainly based on "foreclosure to competition outside the tying-tied product pair" (italics original) and Fumagalli et al. (2018) state that "the Commission could have spelled out its theory of harm in a clearer way." Our model of complementary products can be used to provide a coherent theory of harm in this case by explicitly acknowledging the two-sidedness of the media player market. As typical in two-sided markets, media players on the consumer side are subsidized with a zero price. Instead, the main sources of revenues are "content encoding software, format licensing, wireless information device software, DRM solutions and online music delivery" while the

incentive to lower its price. Under the assumption of $u+v_{1}>\beta$ combined with $G(\Delta) / g(\Delta) \leq \beta$, we can prove that conditional on deviating to a price higher than the equilibrium price, the profit decreases with the price. Finally, we can show that an infinitesimal increase from the equilibrium price strictly reduces the profit, implying that there is no profitable deviation.

${ }^{31}$ See the European Commission Press Release entitled "Commission concludes on Microsoft investigation, imposes conduct remedies and a fine," (IP/04/382) released on March 24, 2004. Available at http://europa.eu/rapid/press-release_IP-04-382_en.htm?locale=en 
media player market serves as "a strategic gateway to a range of related markets." ${ }^{32}$ The additional revenues coming from these related markets can be captured by the parameter $\beta$ in our model. The remedy imposed by the Commission can also be rationalized by our model. In addition to a fine of 497 million Euro, the Commission required Microsoft to offer a version of its Windows PC operating system without Windows Media Player (WMP). In particular, Microsoft was not allowed to offer consumers a discount conditional on their buying Windows together with WMP. This requirement can be interpreted as shutting down a channel through which Microsoft can engage in de facto pure bundling because mixed bundling with a deep enough discount has the same effect as pure bundling. ${ }^{33}$

Carlton and Waldman's (2012) model may also support the Commission's decision in this case. ${ }^{34}$ They develop a related model of imperfect rent extraction based on product upgrades. In their dynamic model, tying provides a mechanism to foreclose competition in the development and supply of rival complementary products, thereby allowing the tying firm to extract surplus from its own product upgrades in the future. Without tying, the rival realizes the rent from upgrading in the future, which the incumbent cannot extract by charging a high price for the primary product in the current period. The main reason for imperfect rent extraction in their model is the assumption that consumers in the current period are not willing to pay for the additional utility to be generated in the future. In addition, the tying firm is assumed not to be able to set prices contingent on the realization of upgrading or the development of a new complementary product in the future. In the WMP case, however, all media players including the major rival product Real Player in the market were available at a zero price. Moreover, subsequently upgraded products were also supplied at a zero price, which makes their model of one-sided market less directly applicable. In particular, their model cannot be applied if the additional rents are generated contemporaneously since then the rents can be extracted through price squeeze. ${ }^{35}$ However, in the WMP case, the rents can arise contemporaneously from the sale of additional complementary products such as content encoding software or format licensing.

\footnotetext{
${ }^{32}$ Commission Decision of 24.03.2004 relating to a proceeding under Article 82 of the EC Treaty (Case COMP/C-3/37.792 Microsoft), Para 975.

${ }^{33}$ See also Ayres and Nalebuff (2005) for a discussion of the remedy.

${ }^{34}$ See Fumagalli et al. (2018), pp. 453-456, for a more detailed discussion of the case.

${ }^{35}$ They show that in the case of leasing (i.e. the incumbent can choose a price for the primary product each period), the incumbent has no strict incentive to tie.
} 


\subsubsection{The Google Shopping Case}

A variation of our model can also be applied to provide a theory of harm in the Google shopping case if we interpret Google's prominence to its own shopping service as tying "Google search" with "Google shopping." 36 We can consider $\alpha$ as the advertising revenue brought by consumers using a general search engine (market $A$ ) and $\beta$ the revenue brought by clicking on 'shopping' (or price comparison site) web pages (market $B$ ). In this case, we can impose a zero price constraint on both markets as both general search and price comparison sites do not charge users directly. With this simple modification, regardless of whether we consider general search and shopping sites independent or complementary products, Google's profit without tying is $\alpha$ while its profit with tying is $\alpha+\beta$. Tying reduces consumer surplus and welfare because users' choices are restricted. ${ }^{37}$

\section{Applications to Other Markets with Ancillary Revenues}

We have developed a leverage theory of tying in the context of two-sided markets. However, our insight can be applied to any market in which sales to consumers in one market can generate additional revenues that cannot be competed away due to non-negative price constraints. This additional revenue came from the other side of the market in the case of a two-sided market. The additional revenues can also be generated in an intertemporal context with the other market being the same market in the future. To illustrate this idea, we present two variations of the baseline model with $\alpha=\beta=0$.

\subsection{Tying in Markets with (Direct) Network Effects}

Market $A$ is the same as in the baseline model. Market $B$ is characterized with network effects. We adopt a simplified and modified version of Katz and Shapiro's (1986) dynamic technology adoption model with network effects for market $B$. Let us assume a stationary environment with respect to both firms' technologies. ${ }^{38}$ There are two periods with the discount factor of $\delta$. In period $t(=1,2), N^{t}$ consumers of generation $t$ make a purchase decision. For simplicity, assume $N^{1}=N^{2}$. Each period, two firms compete with

\footnotetext{
${ }^{36}$ See the European Commissioin Press Release IP/17/1784 (June 27, 2017) and Fumagalli (2017).

${ }^{37}$ We thank Massimo Motta for suggesting the applicability of our model to the Google shopping case. See also Iacobucci and Ducci (2019) for an in-depth discussion of this case.

${ }^{38}$ In contrast, Katz and Shapiro (1986) assume a situation in which one technology is better than the other in the first period but becomes inferior in the second period to derive interesting dynamics.
} 
incompatible products $B 1$ and $B 2$. A consumer who purchases product $B 1$ in period $t$ derives net benefits of $v_{1}+\phi\left(x^{1}+x^{2}\right)-p_{1}^{t}$, and the corresponding value from product $B 2$ is given by $v_{2}+\phi\left(y^{1}+y^{2}\right)-p_{2}^{t}$, where $x^{t}$ and $y^{t}$ denote the quantities of product $B 1$ and $B 2$, respectively, sold in period $t$. Consumers have the same preferences and coordinate on the Pareto-efficient outcome when there are multiple equilibria. Once again, firms' production costs are zero in all markets and $\Delta=v_{2}-v_{1}>0$.

In the absence of tying, firm 1 charges a price of $p_{1}^{A}=u$ in its monopolized market $A$. In market $B$, suppose that firm 1 has captured market $B$ in the first period. This confers firm 1 an installed-base advantage in period 2. Let us assume that this installed-base advantage is sufficiently large such that $\phi^{b}-\phi^{2}>\Delta$, where $\phi^{b}=\phi\left(N^{1}+N^{2}\right)$ and $\phi^{t}$ $=\phi\left(N^{t}\right)$. Then, firm 1 will be able to maintain its market dominance with a price of $\left(\phi^{b}-\phi^{2}\right)-\Delta$. If firm 2 has captured market B in the first period, it can maintain the dominance at a price of $\left(\phi^{b}-\phi^{2}\right)+\Delta$.

Now consider market competition in the first period. If firm 2 decides to capture the market in period 1 , its price needs to satisfy

$$
v_{1}+\phi^{b}-p_{1}^{1} \leq v_{2}+\phi^{b}-p_{2}^{1} .
$$

Firm 1 is willing to charge a price equal to $-\delta\left[\left(\phi^{b}-\phi^{2}\right)-\Delta\right]<0$. However, the nonnegative price constraint limits its price at zero. Given this, firm 2 is able to sell at a price of $\Delta$ in the first period. As a result, each firm's overall profit is given by

$$
\begin{aligned}
\Pi_{1} & =(1+\delta) u \\
\pi_{2}^{B} & =\Delta+\delta\left[\left(\phi^{b}-\phi^{2}\right)+\Delta\right] .
\end{aligned}
$$

Now suppose that firm 1 ties its monopolized product $A$ with product $B 1$. Consider a subgame in which all consumers bought the bundle in the first period. Let $\widetilde{P}^{2}$ and $\widetilde{p}_{2}^{2}$ denote the bundle price and firm 2's price for product $B$ in period 2 under tying. Then, firm 1 will be able to sell its bundled products if

$$
u+v_{1}+\phi^{b}-\widetilde{P}^{2} \geq v_{2}-\widetilde{p}_{2}^{2}+\phi^{2}
$$

Since firm 2 will be willing to set the price as low as its marginal cost, which is zero, the maximum price firm 1 can charge for its bundle in order to make sales is given by 
$\widetilde{P}^{2}=u-\Delta+\left(\phi^{b}-\phi^{2}\right)$. Under tying, firm 1's profit in the second period is given by

$$
\widetilde{\Pi}_{1}^{2}=u-\Delta+\left(\phi^{b}-\phi^{2}\right)>u
$$

If consumers bought from firm 2 in period 1 , the maximum price firm 1 can charge for its bundle in order to make sales is given by $\widetilde{P}^{2}=u-\Delta-\left(\phi^{b}-\phi^{2}\right)$, which is assumed to be positive with a sufficiently high $u$. Firm 1's profit in period 2 in this subgame is given by

$$
\widetilde{\Pi}_{1}^{2}=u-\Delta-\left(\phi^{b}-\phi^{2}\right)
$$

Consider competition in period 1 under tying. If firm 1 decides to capture the market in period 1 , its price needs to satisfy

$$
u+v_{1}+\phi^{b}-\widetilde{P}^{1} \geq v_{2}+\phi^{1}-\widetilde{p}_{2}^{1} .
$$

Note that $\phi^{b}$ is present on the LHS but $\phi^{1}$ on the RHS because firm 1 captures the second period market regardless of who wins the first-period one. Therefore, the highest price that allows firm 1 to capture the market in period one is $\widetilde{P}^{1}=u-\Delta+\left(\phi^{b}-\phi^{1}\right)$. In this case, firm 1's overall profit is given by

$$
\widetilde{\Pi}_{1}=\widetilde{\Pi}_{1}^{1}+\widetilde{\Pi}_{1}^{2}=(u-\Delta)+\left(\phi^{b}-\phi^{1}\right)+\delta\left[u-\Delta+\left(\phi^{b}-\phi^{2}\right)\right]
$$

In contrast, if firm 1 gives up the market in period 1 , its profit becomes $\widetilde{\Pi}_{1}=\widetilde{\Pi}_{1}^{1}+\widetilde{\Pi}_{1}^{2}=$ $0+\delta\left(u-\Delta-\left(\phi^{b}-\phi^{2}\right)\right)$. Thus, firm 1 chooses the first option. Therefore, tying can be profitable if the following condition holds

$$
\widetilde{\Pi}_{1}=(u-\Delta)+\left(\phi^{b}-\phi^{1}\right)+\delta\left(u-\Delta+\left(\phi^{b}-\phi^{2}\right)\right)>(1+\delta) u=\Pi_{1},
$$

that is,

$$
\left(\phi^{b}-\phi^{1}\right)+\delta\left(\phi^{b}-\phi^{2}\right)>(1+\delta) \Delta .
$$

If $N^{1}=N^{2}$ with $\phi^{1}=\phi^{2}$, this condition simplifies to

$$
\phi^{b}-\phi^{2}>\Delta \text {. }
$$

Carlton and Waldman (2002) develop a related model of tying for complementary products in the presence of network effects. However, in their model tying is strategically 
used to preserve monopoly power rather than extend monopoly power to another market. In their model, for some parameter constellations the monopolist need not actually tie its products and can achieve the same goal with a virtual tie by charging a "high" price for the tying product and a "low" price for the tied product because they consider complementary products. They point out that a real tie is needed when the non-negativity constraint for the tied product is binding but do not systematically explore implications of the nonnegativity constraint as we do in the current paper. ${ }^{39}$

\subsection{Tying in Markets with Switching Costs}

Market $A$ is the same as in the baseline model, monopolized by firm 1 with consumers having valuation of $u$ for the product. Market $B$ is one-sided but characterized with a switching costs of $s$ (Klemperer, 1990). We consider a two-period model with a discount factor of $\delta$. Once again, firms' production costs are zero in all markets.

In the absence of tying, firm 1 charges a price of $p_{1}^{A}=u$ in its monopolized market $A$. In market $B$, we apply backward induction to derive the equilibrium. Suppose that firm 1 has captured market $B$ in the first period. In the second period, consumers need to pay a switching cost of $s$ to buy from firm 2 . To illustrate the idea in the simplest manner, let us assume that $s>\Delta=v_{2}-v_{1}>0$ and $(s-\Delta)<u$. In this case, firm 1 will be able to maintain its market dominance with a price of $(s-\Delta)$. If firm 2 has captured market $\mathrm{B}$ in the first period, it can maintain the market at a price of $(s+\Delta)$.

Now consider market competition in the first period. For analytical simplicity, we assume myopic consumers. Firm 1 is willing to charge a price which is $-(s-\Delta)<0$. However, the non-negative price constraint limits its price at zero. Given this, firm 2 is able to sell at a price of $\Delta$ in the first period. As a result, each firm's overall profits are given by

$$
\begin{aligned}
& \Pi_{1}=(1+\delta) u \\
& \pi_{2}^{B}=\Delta+\delta(s+\Delta)
\end{aligned}
$$

Now suppose that firm 1 ties its monopolized product $A$ with product $B 1$. Consider a subgame in which all consumers bought the bundle. Let $\widetilde{P}^{2}$ and $\widetilde{p}_{2}^{2}$ denote the bundle

\footnotetext{
${ }^{39}$ They also provide a model with network effects in which strategic tying is used to extend monopoly power to the newly emerging market. However, their logic applies only when the tying and the tied products are complementary and the new product in the emerging market is a perfect substitute for a system consisting of the tying and the tied products.
} 
price and firm 2's price for product $B 2$ in period 2 under tying. Then, firm 1 will be able to sell its bundled products if

$$
u+v_{1}-\widetilde{P}^{2} \geq v_{2}-\widetilde{p}_{2}^{2}-s
$$

Since firm 2 will be willing to set the price as low as its marginal cost, which is zero, the maximum price firm 1 can charge for its bundle in order to make sales is given by $\widetilde{P}^{2}=u-\Delta+s$. Under tying, firm 1's profits in the second period are given by

$$
\widetilde{\Pi}_{1}^{2}=u-\Delta+s>u
$$

If consumers bought from firm 2 in period 1, the maximum price firm 1 can charge for its bundle in order to make sales is given by $\widetilde{P}^{2}=u-\Delta-s$. Firm 1 's profits in period 2 in this subgame is given by

$$
\widetilde{\Pi}_{1}^{2}=u-\Delta-s
$$

Consider competition in period 1 under tying. If firm 1 decides to capture the market in period 1 , its price needs to satisfy

$$
u+v_{1}-\widetilde{P}^{1} \geq v_{2}-\widetilde{p}_{2}^{1}
$$

This implies that the highest price firm 1 can charge in period 1 and still capture the market is given by $\widetilde{P}^{1}=u-\Delta$. In this case, firm 1 's overall profit is given by

$$
\widetilde{\Pi}_{1}=\widetilde{\Pi}_{1}^{1}+\widetilde{\Pi}_{1}^{2}=(u-\Delta)+\delta(u-\Delta+s)
$$

In contrast, if firm 1 gives up the market in period 1 , its profit becomes $\widetilde{\Pi}_{1}=\widetilde{\Pi}_{1}^{1}+\widetilde{\Pi}_{1}^{2}=$ $0+\delta(u-\Delta-s)$. Thus, firm 1 chooses the first option. Therefore, tying can be profitable if the following condition holds

$$
\widetilde{\Pi}_{1}=(u-\Delta)+\delta(u-\Delta+s)>(1+\delta) u=\Pi_{1}
$$

which can be written as

$$
\begin{aligned}
& s>\frac{1+\delta}{\delta} \Delta . \\
& s>\frac{1+\delta}{\delta} \Delta .
\end{aligned}
$$




\section{Heterogenous Consumers in the Tying Market}

In this section, we consider heterogeneous consumers in market $A$. To derive a closed-form solution, we assume that $u$ is uniformly distributed on $[0,1]$, which yields a linear demand function in market $A .^{40}$ Market $\mathrm{B}$ is modeled as in the baseline model.

In the absence of tying, the two platform markets can be analyzed independently. In market $B$, the analysis is the same as in Section 2. In market $A$, firm 1 chooses $p$ on the consumer side to maximize

$$
\max _{p}(p+\alpha)(1-p)
$$

Under the non-negativity constraint on price, the monopolistic platform's optimal price is given by

$$
p^{m}=\left\{\begin{array}{l}
\frac{1-\alpha}{2} \text { if } \alpha<1 \\
0 \text { otherwise }
\end{array}\right.
$$

The optimal price in the consumer side decreases with the importance of advertising revenue $(\alpha){ }^{41}$

Therefore, without tying, each firm's profit is given by

$$
\begin{aligned}
& \Pi_{1}=\pi^{m}=\left\{\begin{array}{c}
\frac{(1+\alpha)^{2}}{4} \text { if } \alpha<1 \\
\alpha \text { otherwise }
\end{array} ;\right. \\
& \pi_{2}=\Delta+\beta .
\end{aligned}
$$

We assume $\Delta<1 / 2$. Under the assumption, if both firms charge zero price under tying, firm 1's market share is larger than a half. Hence, this assumption implies that firm 1 has a significant ability to leverage its monopoly power to market $B$.

\subsection{Equilibrium under Tying}

Now suppose that firm 1 engages in tying on the consumer side. Consumers have two choices: they can buy a bundled product/service from firm 1 or buy only product/service $B$ from firm 2. Let $\widetilde{P}$ and $\widetilde{p}_{2}$ be the bundle price by firm 1 and product $B$ price by firm

\footnotetext{
${ }^{40}$ The uniform distribution assumption is made for simplicity to derive a closed-form solution in our model. We can derive qualitatively similar results with a more general distribution of $u$.

${ }^{41} \mathrm{We}$ can assume a more general distribution of $u$. If $u$ is distributed according to cdf $G($.$) , the$ maximization problem becomes $\max _{p}(p+\alpha)[1-G(p)]$ and the optimal price is characterized by $p^{m}=$ $\frac{1-G\left(p^{m}\right)}{g\left(p^{m}\right)}-\alpha$. With a monotone hazard rate condition, it can be shown that $p^{m}(\alpha)$ is decreasing in $\alpha$.
} 
2 , respectively. The consumer type $u^{*}$ who is indifferent between the bundled offering and firm 2's single product offering satisfies the following condition:

$$
\left(u^{*}+v_{1}\right)-\widetilde{P}=v_{2}-\widetilde{p}_{2},
$$

which is equivalent to

$$
u^{*}=\left(\widetilde{P}-\widetilde{p}_{2}\right)+\Delta .
$$

As the bundle will be bought by consumers with valuations $u \geq u^{*}$, the demand for the bundle is given by

$$
D\left(\widetilde{P}, \widetilde{p}_{2}\right)=\left\{\begin{array}{cc}
1-u^{*}=1-\left[\left(\widetilde{P}-\widetilde{p}_{2}\right)+\Delta\right] & \text { if } 0 \leq\left(\widetilde{P}-\widetilde{p}_{2}\right)+\Delta \leq 1 \\
1 & \text { if } 0 \leq \widetilde{P}<\widetilde{p}_{2}-\Delta \\
0 & \text { if } \widetilde{P}>1+\widetilde{p}_{2}-\Delta
\end{array}\right.
$$

Firm 2's demand is $1-D\left(\widetilde{P}, \widetilde{p}_{2}\right)$. We have:

Lemma 1. Under tying

(i) Firm 1's best response is given by

$$
B R_{1}\left(\widetilde{p}_{2}\right)=\left\{\begin{array}{cc}
\frac{(1-\Delta)-(\alpha+\beta)+\widetilde{p}_{2}}{2} & \text { for } \Delta+[1-(\alpha+\beta)] \geq \widetilde{p}_{2}>\Delta-[1-(\alpha+\beta)] ; \\
\max \left[0, \widetilde{p}_{2}-\Delta\right] & \text { otherwise. }
\end{array}\right.
$$

(ii) Firm 2's best response is given by

$$
B R_{2}(\widetilde{P})=\max \left[\frac{(\Delta-\beta)+\widetilde{P}}{2}, 0\right]
$$

Therefore, we have to distinguish four cases depending on whether or not $1-\Delta>\alpha+\beta$ and/or $\Delta>\beta$. Let $\left(\widetilde{P}^{\circ}, \widetilde{p}_{2}{ }^{\circ}\right)$ be the solution of

$$
\begin{aligned}
\widetilde{P} & =\frac{(1-\Delta)-(\alpha+\beta)+\widetilde{p}_{2}}{2} \\
\widetilde{p}_{2} & =\frac{(\Delta-\beta)+\widetilde{P}}{2} .
\end{aligned}
$$


That is,

$$
\begin{aligned}
& \widetilde{P}^{\circ}=-\beta+\frac{2(1-\alpha)-\Delta}{3} \\
& {\widetilde{p}_{2}}^{\circ}=-\beta+\frac{1-\alpha+\Delta}{3}
\end{aligned}
$$

Then, depending on the relative magnitudes of two-sidedness parameters ( $\alpha$ and $\beta$ ) and vertical differentiation parameter $\Delta$, we have the following four cases for equilibrium prices under tying.

Case 1 (Both $\alpha$ and $\beta$ Small): $1-\Delta>\alpha+\beta$ and $\Delta>\beta$.

In this case, the non-negative price constraints are not binding and we have $\widetilde{P}^{*}=$ $\widetilde{P}^{\circ}(>0)$ and $\widetilde{p}_{2}^{*}=p^{\circ}(>0)$.

Case 2 (Both $\alpha$ and $\beta$ Large): $1-\Delta<\alpha+\beta$ and $\Delta<\beta$.

$$
\widetilde{P}^{*}=0, \widetilde{p}_{2}^{*}=0
$$

Case 3 (Small $\alpha$ and Large $\beta$ ): $1-\Delta>\alpha+\beta$ and $\Delta<\beta$.

In this case, it can be easily shown that $\widetilde{P}^{\circ}>\widetilde{p}_{2}{ }^{\circ}$. Thus, the non-negative price constraint is binding first for the rival firm's price under tying. We then have the following result.

(i) If $\beta<\frac{(1-\alpha)+\Delta}{3}$,

$$
\widetilde{P}^{*}=\widetilde{P}^{\circ}>0, \widetilde{p}_{2}^{*}=\widetilde{p}_{2}^{\circ}>0
$$

(ii) If $\beta>\frac{(1-\alpha)+\Delta}{3}$,

$$
\widetilde{P}^{*}=B R_{1}(0)=\frac{(1-\Delta)-(\alpha+\beta)}{2}, \widetilde{p}_{2}^{*}=0 .
$$

Case 4 (Large $\alpha$ and Small $\beta$ ): $1-\Delta<\alpha+\beta$ and $\Delta>\beta$.

This is the opposite of case 3 and the non-negative price constraint is binding first for the tying firm as $\widetilde{P}^{\circ}<\widetilde{p}_{2}{ }^{\circ}$. We have the following result.

(i) If $\beta<\frac{2(1-\alpha)-\Delta}{3}$,

$$
\widetilde{P}^{*}=\widetilde{P}^{\circ}>0, \widetilde{p}_{2}^{*}=\widetilde{p}_{2}{ }^{\circ}>0 .
$$

(ii) If $\beta>\frac{2(1-\alpha)-\Delta}{3}$, 


$$
\widetilde{P}^{*}=0, \widetilde{p}_{2}^{*}=B R_{2}(0)=\frac{\Delta-\beta}{2} .
$$

The equilibrium price configurations under tying are summarized in Figure 1.

\subsection{Incentives to Tie in Two-Sided Markets}

We now analyze the monopolistic firm's incentives to tie for each price configuration regime.

- Case of $\widetilde{P}^{*}=0$ and $\widetilde{p}_{2}^{*}=0$

This case corresponds to a situation in which both firms' non-negative price constraints are binding under tying because both $\alpha$ and $\beta$ are relatively large compared to $\Delta$ (i.e., when $1-\Delta<\alpha+\beta$ and $\Delta<\beta$ ). With these prices, each firm's market demand under tying is given by

$$
\widetilde{D}_{1}=1-\Delta \text { and } \widetilde{d}_{2}=\Delta
$$

Each firm's corresponding profit under tying is given by

$$
\begin{gathered}
\widetilde{\Pi}_{1}=(1-\Delta)(\alpha+\beta) ; \\
\tilde{\pi}_{2}=\Delta \beta .
\end{gathered}
$$

Profit comparisons lead to:

Lemma 2. Consider the case when the equilibrium prices under tying are given by $\widetilde{P}^{*}=$ $0, \widetilde{p}_{2}^{*}=0$ (i.e., $\alpha+\beta>1-\Delta$ and $\beta>\Delta$ ).

(i) Tying unambiguously reduces the rival firm's profit.

(ii) Firm 1's incentive to tie increases with $\beta$ and decreases with $\alpha$. More precisely, tying is always profitable for $\alpha<(1-2 \Delta)$ and increases firm 1's profit if $\beta>\frac{(1-\alpha)^{2}+4 \alpha \Delta}{4(1-\Delta)}$ for $(1-2 \Delta)<\alpha<1$ and if $\frac{\beta}{\alpha}>\frac{\Delta}{1-\Delta}$ for $\alpha \geq 1$.

Tying reduces firm 2's profit by reducing its market share and its price. Firm 1's incentive to tie increases with $\beta$ since $\widetilde{\Pi}_{1}$ increases with $\beta$ but firm 1 's profit without tying does not depend on $\beta$. This is consistent with the finding from the baseline model. In addition, Lemma 2(ii) shows that firm 1's incentive to tie decreases with $\alpha$ for given $\beta$. This is very clear when $\alpha>1$. Then, in market $A$, tying generates a loss of $\Delta \alpha$ since 


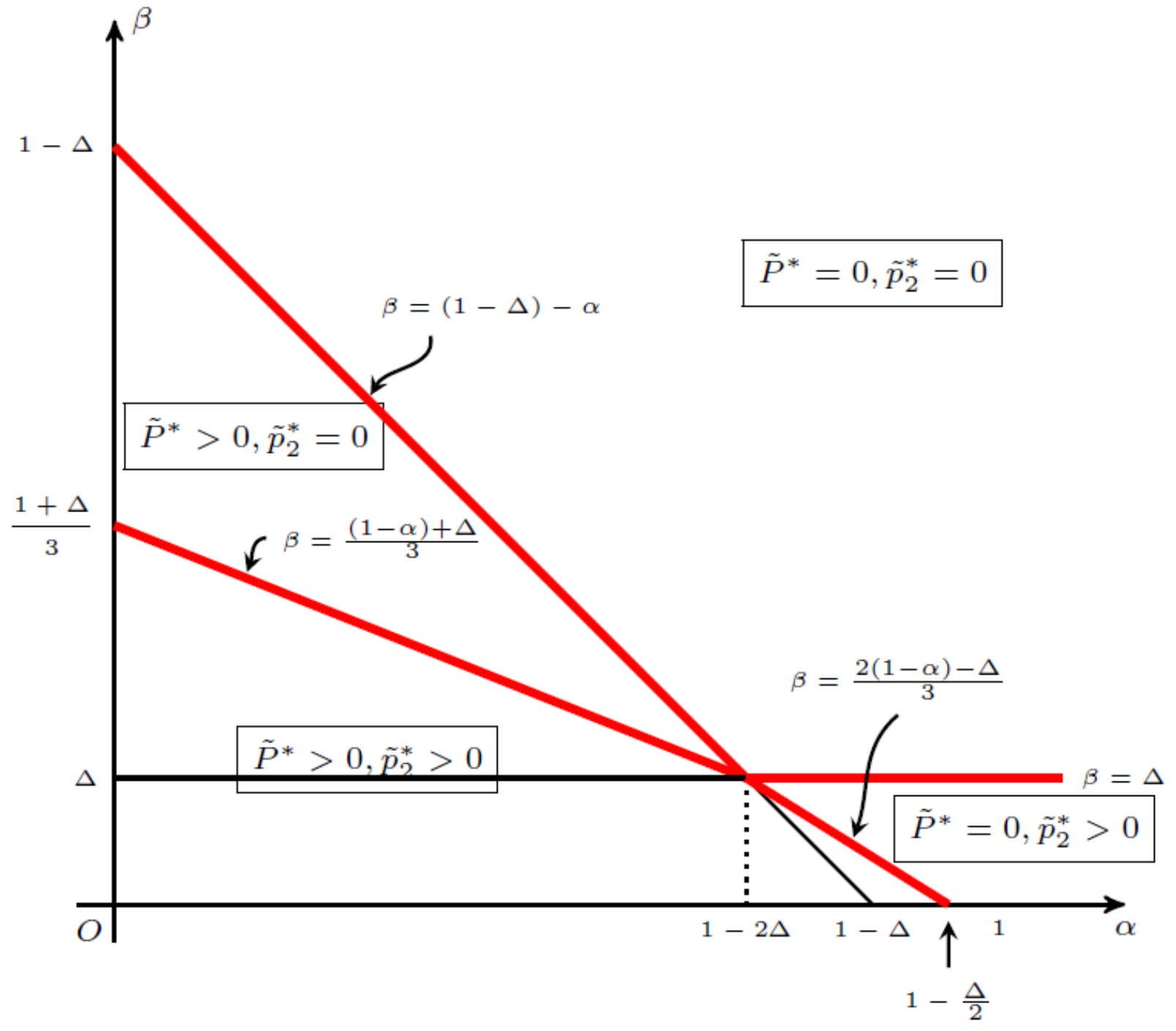

Figure 1: Equilibrium Price Configurations under Tying 
consumers with low valuations for the monopoly product buy firm 2's product instead of the bundle.

$$
\text { - } \widetilde{P}^{*}>0, \widetilde{p}_{2}^{*}=0
$$

This price regime arises when both $\alpha<1-2 \Delta$ and $1-\Delta-\alpha>\beta>(1-\alpha+\Delta) / 3$ hold. The latter condition implies $\beta>\Delta$. Essentially, market $A$ is close to being one-sided while market $B$ is quite two-sided. This case is fundamentally the same as the baseline model and we have:

Lemma 3. When the equilibrium prices under tying are given by $\widetilde{P}^{*}>0$ and $\widetilde{p}_{2}^{*}=0$ (i.e., when both $\alpha<1-2 \Delta$ and $1-\Delta-\alpha>\beta>(1-\alpha+\Delta) / 3$ hold $)$, tying is always profitable for firm 1 whereas tying always reduces the rival firm's profit.

- Case of $\widetilde{P}^{*}>0$ and $\widetilde{p}_{2}^{*}>0$

This price regime arises under tying when both $\alpha$ and $\beta$ are relatively small compared to $\Delta$. More precisely, the following condition needs to hold:

$$
\begin{aligned}
& \beta<\frac{(1-\alpha)+\Delta}{3} \text { if } \alpha<1-2 \Delta \\
& \beta<\frac{2(1-\alpha)-\Delta}{3} \text { if } \alpha>1-2 \Delta
\end{aligned}
$$

In this case, the non-negative price constraint is binding for neither firm as $\widetilde{P}^{*}=\widetilde{P}^{\circ}>$ $0, \widetilde{p}_{2}^{*}=\widetilde{p}_{2}^{\circ}>0$.

Firm 1 and firm 2's demands are respectively given by

$$
\widetilde{D}_{1}=\frac{2+\alpha-\Delta}{3}, \widetilde{d}_{2}=\frac{(1-\alpha)+\Delta}{3} .
$$

The corresponding profits are given by

$$
\widetilde{\Pi}_{1}=\left[\frac{2+\alpha-\Delta}{3}\right]^{2}, \widetilde{\pi}_{2}=\left[\frac{(1-\alpha)+\Delta}{3}\right]^{2} .
$$

Since each firm reduces its price by $\beta, \beta$ is competed away and therefore both firms' profits under tying are independent of $\beta$. Note that the highest $\alpha$ that satisfies the conditions above for this price regime is $\alpha=1-\frac{\Delta}{2}<1$. Hence, firm 1's profit under no tying is $\Pi_{1}=\frac{(1+\alpha)^{2}}{4}$. We have $\widetilde{\Pi}_{1}>\Pi_{1}$ if and only if $\alpha<1-2 \Delta$. The comparison of the 
rival firm's profits shows that $\widetilde{\pi}_{2}>\pi_{2}$ if $\beta<\left[\frac{(1-\alpha)+\Delta}{3}\right]^{2}-\Delta$. We thus have the following lemma.

Lemma 4. Consider the case when the equilibrium prices under tying are given by $\widetilde{P}^{*}>0$ and $\widetilde{p}_{2}^{*}>0$ (i.e., either $\beta<\frac{(1-\alpha)+\Delta}{3}$ and $\alpha<1-2 \Delta$ hold or $\beta<\frac{2(1-\alpha)-\Delta}{3}$ and $\alpha>1-2 \Delta$ hold).

(i) Tying is profitable for firm 1 if and only if $\alpha<1-2 \Delta$.

(ii) Tying increases the rival firm's profits if and only if $\beta<\left[\frac{(1-\alpha)+\Delta}{3}\right]^{2}-\Delta$.

(iii) When $\alpha=\beta=0$, tying is profitable for both firms if $\Delta \lesssim 0.14590$.

Note that the possibility of tying to relax competition and increase both firms' profits can arise only when $\Delta \leq \frac{7-3 \sqrt{5}}{2} \simeq 0.14590$. Lemma 4 implies that when $\Delta$ is small, tying increases both firms' profits if both $\alpha$ and $\beta$ are close to zero (i.e., when both markets are essentially one-sided). For instance, when $\alpha=\beta=0$, Lemma 4(iii) shows that tying increases both firms' profits if and only if $\Delta \lesssim 0.14590$. This result replicates the insight provided by Carbajo et al. (1990) for the case of standard one-sided markets. When firms compete in prices, tying/bundling provides a mechanism to differentiate products. High valuation consumers for the tying product buy the bundled product whereas low valuation consumers just buy the stand-alone product provided by the rival firm in the tied good market. This relaxes competition in the tied good market. This intuition comes out clearly if we consider an extreme case of $\Delta=0$. In this case, the tied good product is homogeneous and the equilibrium price will be driven down to zero (or more generally to $\mathrm{MC}$ if $\mathrm{MC}>0$ ) and both firms receive zero profits in market $B$ in the absence of tying. With tying, both firms can increase profits by segmenting the market.

- Case of $\widetilde{P}^{*}=0$ and $\widetilde{p}_{2}^{*}>0$

This price regime arises when the following condition holds.

$$
\frac{2(1-\alpha)-\Delta}{3}<\beta<\Delta .
$$

The parameter restriction of $\beta<\Delta$ implies that market $B$ is not two-sided enough since the assumption in the baseline model $\beta>\Delta$ is violated. Moreover, the condition implies $1-2 \Delta<\alpha$ (i.e., market $A$ can be quite two-sided). Therefore, tying is not profitable for firm 1. Tying reduces firm 2's profit as well by reducing its price and its market share. 
Lemma 5. When the equilibrium prices under tying are given by $\widetilde{P}^{*}=0$ and $\widetilde{p}_{2}^{*}>0$ (i.e., when $\frac{2(1-\alpha)-\Delta}{3}<\beta<\Delta$ holds), tying reduces both firms' profits.

For $\alpha$ large and $\beta$ small, tying makes both firms more aggressive since the prices under tying are lower than the prices without tying. It thereby reduces both firms' profits, which is reminiscent of the finding of Whinston (1990).

All cases taken together, we can summarize our analysis so far in the following proposition.

Proposition 4. Consider the model in which consumers are heterogenous in terms of their valuations for the monopoly product. Assume $1 / 2>\Delta$.

(i) Firm 1's incentive to tie increases with $\beta$ and decreases with $\alpha$. Specifically, firm 1 has incentives to tie if $\alpha<(1-2 \Delta)$. For $\alpha \in(1-2 \Delta, 1)$, tying is profitable if $\beta>$ $\frac{(1-\alpha)^{2}+4 \alpha \Delta}{4(1-\Delta)}$. For $\alpha>1$, tying is profitable if $\frac{\beta}{\alpha}>\frac{\Delta}{1-\Delta}$.

(ii) Tying is more likely to reduce firm 2's profit as $\alpha$ increases and as $\beta$ increases. Specifically, tying reduces firm 2's profit unless $\beta<\left[\frac{(1-\alpha)+\Delta}{3}\right]^{2}-\Delta$ and $\alpha<(1-2 \Delta)$.

The area in which tying is not profitable for firm 1 is represented by the shaded area in the right bottom corner of Figure 2. In all other areas tying is profitable. For the rival firm, the area in which tying is profitable is represented as the triangle area near the origin in Figure 2. In all other areas tying reduces the rival firm's profit.

We make two remarks from our analysis. First, tying is profitable and reduces the rival's profit if $\beta$ in the tied good market is sufficiently large. As a result, our leverage mechanism does not have any credibility issue, in sharp contrast to the tying literature in one-sided markets (Whinston (1990) and Nalebuff (2004)). More specifically, our mechanism does require neither technical tying as a commitment device as in Whinston (1990) nor the controversial assumption that the tying firm is a Stackelberg leader in setting prices as in Nalebuff (2004). The use of contractual tying, even if it can be easily undone, is sufficient for credible leverage. Second, tying reduces both firms' profits if $\alpha$ in the tying good market is sufficiently large (relative to $\beta$ ). In the next section, we will investigate how this second result is affected by the presence of inter-group network effects.

\subsection{Welfare Analysis}

The welfare effects of tying in our model depend on whether or not the monopoly price in market $A$ is already zero (i.e., $\alpha \geq 1$ ) in the absence of tying. 


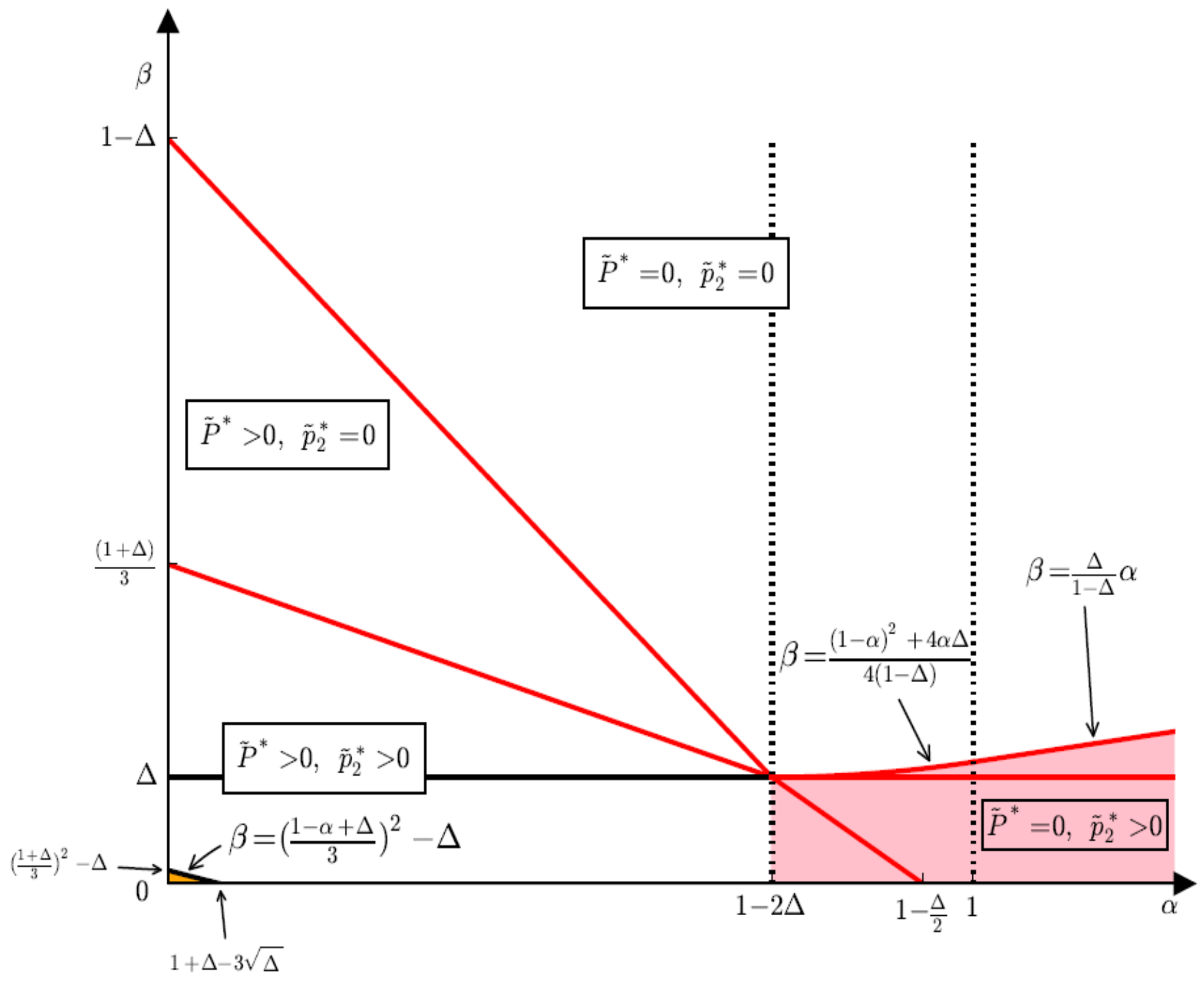

Figure 2: Incentives to Tie in Two-Sided Markets 
Case 1. (Full Market Coverage Case without Tying) $\alpha \geq 1$

For $\alpha \geq 1$, the price in market $A$ is zero and all consumers enjoy the service without tying, which is an efficient outcome. The equilibrium in market $B$ is also efficient without tying because all consumers use the more efficient service provided by firm 2 . Therefore, tying can only reduce social welfare. From Proposition 4, we know that for $\alpha \geq 1$, firm 1 has incentives to engage in tying only for the parameter values such that the post-tying equilibrium prices are characterized by $\widetilde{P}^{*}=0, \widetilde{p}_{2}^{*}=0$ (see Figure 2). In this case, there are two sources of inefficiencies. First, any consumer whose valuation in market $A$ is less than $\Delta$ purchases from firm 2 and consumes only product $B$. Second, consumers whose valuation in market $A$ is more than $\Delta$ inefficiently switch from firm 2's more efficient product to the bundled product. Note that consumer surplus increases in this case due to a decrease in the price of firm 2's product from $\Delta$ to zero. Consumers whose valuation in market $A$ is more than $\Delta(u>\Delta)$ are indifferent between the two regimes, but low type consumers in market $A$ (whose $u<\Delta$ ) gain with tying because their utility is $v_{2}$ with tying while it was $u+v_{1}$ without tying.

Case 2. (Partial Market Coverage Case without Tying) $\alpha<1$

When $\alpha<1$, the price in market $A$ is positive without tying and the market outcome is inefficient whereas the market outcome in $B$ is efficient. As in the previous case, tying can introduce inefficiency in market $B$ when firm 1 inefficiently serves consumers with a bundled product, but there can be a positive market expansion effect in market $\mathrm{A}$ as the bundle price is reduced. As a result, social welfare can be ambiguous. However, for social welfare to increase with tying a necessary condition is that market $A$ expands with tying. The next lemma derives the condition under which market $A$ expands with tying.

Lemma 6. Market $A$ expands with tying if and only if $\alpha<1-2 \Delta$.

The immediate corollary of lemma 6 is that tying decreases social welfare if $\alpha>1-2 \Delta$.

Now let us consider the case where $\alpha<1-2 \Delta$ and hence market $A$ expands with tying. More generally, the social welfare change with tying $(\Delta W)$ in this case can be written as

$$
\Delta W=\underbrace{\int_{1-\widetilde{D}_{1}}^{\frac{1-\alpha}{2}}(u+\alpha) d u}_{\begin{array}{c}
\text { Welfare Gain in Market A } \\
\text { due to Market Expansion }
\end{array}}-\underbrace{\widetilde{D}_{1} \Delta}_{\text {Social Welfare Loss in Market B }},
$$


where $\widetilde{D}_{1}$ denotes the demand for the bundle after tying. After analyzing the welfare effects of tying depending on the equilibrium price configurations (see the proof of Proposition 5), we find that tying increases welfare for $\Delta$ small enough as in this case the welfare loss in market B is small.

Proposition 5. Tying is welfare-reducing if $\alpha>1-2 \Delta$ since market $A$ contracts and there is inefficient switching in market $B$. If $\alpha<1-2 \Delta$, market $A$ expands and tying can enhance welfare if $\Delta$ is sufficiently small since inefficiency associated with tying in market $B$ becomes arbitrary small as $\Delta \rightarrow 0$.

\section{Heterogenous Consumers with Intergroup Network Effects}

Up to now, we assumed two-sided markets in which the consumer side serves as a competitive bottleneck but did not derive any direct utilities (or disutilities) from the other side which can be considered as advertisers. This was to capture the advertising revenue-based business model of many Internet platform markets such as Google. In this section, we extend our analysis by explicitly considering intergroup network effects from the other side to consumers. For instance, we can interpret the other side as app producers or content providers. In the presence of network effects, consumers' choices can exhibit strategic complementarity and coordination plays an important role. In such a situation, tying can be used as a strategic instrument to help consumers coordinate and coalesce around the bundled product. We investigate how the presence of network effects affects the previous results on the relationship between the incentive to tie and $\alpha$ (and $\beta$ ).

For simplicity, we assume that the monopolistic platform market $A$ is the same as in Section 4 . We modify market $B$ as follows. Let $p_{i}^{c}$ be the price charged by platform $i$ on the consumer side in market $B$. Then, a consumer subscribing to platform $i$ in market $B$ derives a utility of

$$
v_{i}+\beta_{c} n_{i}^{a}-p_{i}^{c}
$$

where $\beta_{c}(>0)$ is a parameter representing intergroup network effects and $n_{i}^{a}$ is the measure of applications/content available at platform $i$. We assume $\Delta \equiv v_{2}-v_{1}>0$. On the application side, let $p_{i}^{a}$ be the price an application developer needs to pay to have access to consumers on platform $i$. An application developer's payoff from developing an application or creating content for platform $i$ is 


$$
\beta_{a} n_{i}^{c}-p_{i}^{a}
$$

where $\beta_{a}>0$ and $n_{i}^{c}$ is the measure of consumers on platform $i$. Marginal costs of serving consumers are once again assumed to be zero.

In order capture the idea of competitive bottleneck, we consider the following sequential game.

1. Each firm (i.e., platform) sets the prices for consumers.

2. Consumers make purchase or subscription decisions

3. (After observing consumer choices at stage 2), each platform chooses the price for application developers

4. (After observing consumer choices at stage 2 and price choices at stage 3 ), application developers choose subscription decisions.

Under the timing, stages 1 and 2 of the game are identical to the games we studied in the previous sections. The main difference is that the advertising revenue per consumer in market $B$ was exogenously given in the previous sections whereas its equivalent is now endogenous: solving for Stages 3 and 4 allows us to compute the additional profit that a platform can obtain from the application side by attracting one more consumer. We assume that consumers single home while application developers can multihome. As usual, we analyze the game by using backward induction.

\subsection{Equilibrium on the Application Side}

Suppose that platform $i$ has $n_{c}^{i}$ measure of consumers on board. Let us study the game that starts at stage 4 .

In order to endogenously derive the number of applications available, we assume that each developer incurs a platform-specific fixed cost $f$. The fixed cost is distributed over the positive line with density equal to one. Given the heterogeneity in the fixed cost of development, an application developer will subscribe to platform $i$ if the following condition holds:

$$
\beta_{a} n_{i}^{c}-p_{i}^{a} \geq f
$$

Hence, given $n_{i}^{c}$ and $p_{i}^{a}$, the total measure of app developers who subscribe to platform $i$ is

$$
n_{i}^{a}\left(p_{i}^{a} ; n_{i}^{c}\right)=\beta_{a} n_{i}^{c}-p_{i}^{a}
$$


Therefore, at stage 3 with $n_{i}^{a}$ determined in the previous stage, platform $i$ solves the following problem.

$$
\max _{p_{i}^{a}} p_{i}^{a} n_{i}^{a}\left(p_{i}^{a} ; n_{i}^{c}\right)=p_{i}^{a}\left(\beta_{a} n_{i}^{c}-p_{i}^{a}\right) .
$$

From the first-order condition for platform $i$ 's profit maximization, platform $i$ chooses

$$
p_{i}^{a}=\frac{\beta_{a} n_{i}^{c}}{2} .
$$

The measure of app developers who subscribe to platform $i$ also is given by $n_{i}^{a}=\frac{\beta_{a} n_{i}^{c}}{2}$ with a uniform distribution of $f$ with density one. As a result, given the number of consumers $n_{i}^{c}$, platform $i$ 's profit on the application side is

$$
\pi_{i}^{a}\left(n_{i}^{c}\right)=\left(\frac{\beta_{a} n_{i}^{c}}{2}\right)^{2}
$$

Note that this result does not depend on whether or not there is tying on the consumer side.

\subsection{Equilibrium on the Consumer Side}

We now analyze the effects of tying on the consumer side.

\subsubsection{No Tying}

Consider platform competition at stage 1 without tying. As we assume that all consumers are homogenous in market $B$, there can potentially be multiple equilibria for some price configurations due to positive intergroup network effects. In such cases, we assume that all identical consumers coordinate on the Pareto dominant equilibrium. ${ }^{42}$

Hence, if $p_{2}^{c}<p_{1}^{c}+\Delta$, all consumers coordinate on platform 2 as long as their individual rationality constraint is satisfied. Therefore, in equilibrium, we have $p_{1}^{c}=0, p_{2}^{c}=\Delta$ and all consumers join the more efficient platform 2, that is, $n_{1}^{c}=0$ and $n_{2}^{c}=1$. In this tipping equilibrium with $n_{2}^{c}=1$, firm 2 charges $p_{2}^{a}=\frac{\beta_{a} n_{2}^{c}}{2}=\frac{\beta_{a}}{2}$ on the application side and induces a measure of $n_{2}^{a}=\frac{\beta_{a}}{2}$ application developers to be on its platform. Thus,

\footnotetext{
${ }^{42}$ This is a standard equilibrium selection criterion in the presence of multiple equilibria with network effects. See, for instance, Katz and Shaprio (1986) and Waldman (1993).
} 
each consumer's payoff on platform 2 is

$$
v_{2}+\beta_{c} n_{2}^{a}-p_{2}^{c}=v_{2}+\beta_{c}\left(\frac{\beta_{a}}{2}\right)-\Delta=v_{1}+\eta,
$$

where $\eta \equiv \frac{\beta_{c} \beta_{a}}{2}$ represents the network benefits in the tipping equilibrium. As in the analysis of the previous section, each consumer receives a surplus of $v_{1}$ due to platform competition on the consumer side. In addition, each consumer receives additional benefit of $\eta=\frac{\beta_{c} \beta_{a}}{2}$ from intergroup network effects.

\subsubsection{Tying}

Now consider the equilibrium in the tying regime in which platform 1 ties its monopolized product $A$ with another product in competitive two-sided market $B$, and charges $\widetilde{P}$ for the bundled product. We make the following assumption:

Assumption 1. (stability) $\beta_{c} \beta_{a}<1 \Leftrightarrow \eta<1 / 2$

Without this assumption, there cannot exist any interior equilibrium in which both platforms share the market in our two-sided market. This is because the feedback mechanism due to intergroup network effects magnifies any initial advantage of one platform and leads to exploding demands.

We further assume that $\Delta<1 / 2$ for tying to have a leverage effect in the tied good market. If $\Delta$ is too large (i.e., $\Delta>1 / 2$ ), the disadvantage of firm 1 vis-à-vis firm 2 is too large to overcome in the tied good market; tying has no leverage effect. Note that $\Delta<1 / 2$ along with the stability assumption implies that purchasing the bundle is the dominant strategy for the highest consumer type in market $A$ (whose $u=1$ ) if the bundle is offered for free. For this type of consumer, the valuation of product $A$ is so high that the bundled product is preferred even if all other consumers purchase stand-alone product $B 2$ and there are no application developers for $B 1$.

Therefore, in what follows, by using iterated elimination of dominated strategies, we study a cut-off equilibrium: we consider a $u^{*} \in[0,1]$ such that all consumers whose valuation from the monopoly product is higher than $u^{*}$ join platform 1 while all the rest join platform 2 , which implies that $n_{1}^{c}=1-u^{*}, n_{2}^{c}=u^{*}$ on the consumer side and $n_{1}^{a}=\frac{\beta_{a}}{2}\left(1-u^{*}\right), n_{2}^{a}=\frac{\beta_{a}}{2} u^{*}$.

Let $\widetilde{P}$ and $\widetilde{p}_{2}$ be the bundle price by firm 1 and firm 2 's price for product $B 2$ in the tying regime, respectively. In the (interior) cut-off equilibrium, $u^{*}$ is implicitly determined 
as follows:

$$
\left[u^{*}+v_{1}\right]+\eta\left(1-u^{*}\right)-\widetilde{P}=v_{2}+\eta u^{*}-\widetilde{p}_{2} .
$$

The LHS of (3) represents type $u^{*}$ consumer's utility when he purchases the bundled product whereas the RHS of (3) represents type $u^{*}$ consumer's utility when he purchases only product $B$ supplied by firm 2 . The critical type $u^{*}$ is indifferent between these two options. Hence,

$$
n_{2}^{c}\left(\widetilde{P}, \widetilde{p}_{2}\right)=u^{*}= \begin{cases}\frac{\Delta+\widetilde{P}-\widetilde{p}_{2}-\eta}{\left(1-\beta_{c} \beta_{a}\right)}, & \text { if } \widetilde{P}>\widetilde{p}_{2}+\eta-\Delta ; \\ 0, & \text { if } \widetilde{P} \leq \widetilde{p}_{2}+\eta-\Delta .\end{cases}
$$

The expression for $n_{2}^{c}$ above reveals new effects of tying in the presence of intergroup network effects. If there are no network effects (i.e., $\beta_{c} \beta_{a}=0$ ), firm 2 can always guarantee a positive market share unless its price does not exceed the bundle price by $\Delta$. For instance, if firm 2 charges a price of zero, firm 2 will always have some positive market share $\left(n_{2}^{c}>0\right)$. However, because of the existence of network externalities (i.e., as the number of consumers who choose platform 1 increases, the applications available on that platform increases), tying can create an advantage for platform 1 if tying provides a mechanism for firm 1 to capture more consumers than firm 2. As the network effects term $\left(\beta_{c} \beta_{a}\right)$ increases, firm 2's market share decreases down to zero and eventually tying leads to the foreclosure of firm 2 in the market. Note that $\frac{\partial n_{2}^{c}}{\partial \widetilde{P}}=\left|\frac{\partial n_{2}^{c}}{\partial \widetilde{p}_{2}}\right|=\frac{1}{1-\beta_{c} \beta_{a}}>1$ is a multiplier in the two-sided market. It shows that the demand changes more sensitively to price as $\beta_{c} \beta_{a}$ increases.

Consider the case where $n_{2}^{c}\left(\widetilde{P}, \widetilde{p}_{2}\right)>0$. Then, we can decompose the market share of the tying firm into two terms as follows:

$$
n_{1}^{c}\left(\widetilde{P}, \widetilde{p}_{2}\right)=1-n_{2}^{c}\left(\widetilde{P}, \widetilde{p}_{2}\right)=\underbrace{1-\left[\left(\widetilde{P}-\widetilde{p}_{2}\right)+\Delta\right]}_{\begin{array}{c}
\text { Demand in the Absence of } \\
\text { Intergroup Network Effects }
\end{array}}+\underbrace{\frac{\beta_{c} \beta_{a}}{\left(1-\beta_{c} \beta_{a}\right)}\left[\frac{1}{2}-\left[\left(\widetilde{P}-\widetilde{p}_{2}\right)+\Delta\right]\right]}_{\begin{array}{c}
\text { Induced Demand Due to } \\
\text { Intergroup Network Effects }
\end{array}},
$$

where $1-\left[\left(\widetilde{P}-\widetilde{p}_{2}\right)+\Delta\right]$ is a hypothetical demand for firm 1 in the absence of intergroup network effects (i.e., $\beta_{c} \beta_{a}=0$ ), which we have seen in Section 4 (see equation (2)).

In order to understand equilibrium pricing, it is useful to decipher the economic meaning of $\Psi \equiv 1-\beta_{c} \beta_{a}-\frac{\left(\beta_{a}\right)^{2}}{2}$. As firm 1's profit under tying is given by $\widetilde{\Pi}_{1}=$ 
$\left[\widetilde{P}+\alpha+\frac{\left(\beta_{a}\right)^{2} n_{1}^{c}}{4}\right] n_{1}^{c}$, its first-order condition for profit maximization is given by:

$$
\frac{\partial \widetilde{\Pi}_{1}}{\partial \widetilde{P}}=\frac{\partial n_{1}^{c}}{\partial \widetilde{P}}\left[\widetilde{P}+\alpha-n_{1}^{c} \Psi\right]=0
$$

where $\frac{\partial n_{1}^{c}}{\partial \widetilde{P}}=-\frac{1}{1-\beta_{c} \beta_{a}}$. We can rewrite the condition above in a modified Lerner index form:

$$
\frac{\widetilde{P}+\alpha}{\widetilde{P}}=\frac{n_{1}^{c} \Psi}{\widetilde{P}} .
$$

If the tying firm did not take into account the effect of its bundle pricing decision on the profit from the application side, $\Psi$ would not contain the term $\frac{\left(\beta_{a}\right)^{2}}{2}$ and we would have $\Psi=1-\beta_{c} \beta_{a}$, which is equal to the inverse of $\left|\frac{\partial n_{1}^{c}}{\partial \widetilde{P}}\right|$. Therefore, we can state the first-order condition as the standard Lerner formula with the interpretation of $(-\alpha)$ as the opportunity cost of the bundle. $\Psi$ corrects the standard formula by taking into account the fact that an increase in market share increases the profit from the application market through the network effects. If this effect is large such that $\Psi \leq 0$, firm 1 finds it optimal to choose $\widetilde{P}=0$ for any $\alpha \geq 0$. The same remark applies to firm 2 . Therefore, $-\Psi$ can be considered a measure of degree of competition induced by intergroup network effects, which increases with the network effects and the profit per consumer from the app market.

We can have two types of equilibria: an interior equilibrium in which firm 1 and firm 2 share the market with $n_{2}^{c}>0$ and the tipping equilibrium in which the tying firm captures the whole market with $n_{2}^{c}=0 .{ }^{43}$ The following proposition characterizes the equilibrium conditions.

Proposition 6. We have a tipping equilibrium (with $n_{1}^{c}=1$ and $n_{2}^{c}=0$ ) if $\eta \geq \Delta$ and $\alpha \geq \widehat{\alpha} \equiv(\Delta-\eta)+\Psi$, where $\Psi=1-\beta_{c} \beta_{a}-\frac{\left(\beta_{a}\right)^{2}}{2}$. Otherwise, we have an interior equilibrium with both $n_{1}^{c}>0$ and $n_{2}^{c}>0$.

In the appendix, we not only prove the proposition above but also further characterize equilibrium prices in each type of equilibrium. Proposition 6 shows that if $\Delta>\eta$, that is, the quality advantage of firm 2 is sufficiently large compared to the strength of network effects, we always have an interior equilibrium. However, if the network effects are relatively stronger than the quality advantage of firm 2 (i.e., $\Delta<\eta$ ), tying can be a mechanism for firm 1 to leverage its market power in $A$ to $B$ and lead to foreclosure

\footnotetext{
${ }^{43}$ With the maintained assumption of $\Delta<1 / 2$ and the stability assumption, there is no tipping equilibrium in which firm 2 captures the whole market.
} 
of the rival firm. Note that the condition for tipping is more likely to be satisfied as $\alpha$ increases. For instance, if $\alpha>1$, we always have a tipping equilibrium as long as $\Delta<\eta$.

\subsection{Incentives to Tie with Intergroup Network Effects}

We now analyze incentives to tie in the presence of intergroup network effects. Proposition 6 shows that when $\Delta \leq \eta$ holds, a tipping equilibrium is more likely as $\alpha$ increases. This is because a high $\alpha$ induces the monopolist to price more aggressively in the consumer market, providing more surplus to inframarginal consumers, which can be leveraged to attract all consumers in market $B$ through network effects (see the demand decomposition in (4)). If tipping occurs, firm 1 captures all advertising revenue in market A, which breaks the result obtained in the previous section that there exists a critical value of $\alpha^{*}$ such that tying is not profitable if $\alpha \geq \alpha^{*}$.

\subsubsection{Tipping Equilibrium}

As shown in Proposition 6, we have a tipping equilibrium if $\Delta \leq \eta$ and $\alpha \geq 1-\left[\left(\beta_{c} \beta_{a}+\right.\right.$ $\left.\left.\frac{\left(\beta_{a}\right)^{2}}{2}\right)+(\eta-\Delta)\right]$. In the tipping equilibrium, $p^{*}=0, P^{*}=\eta-\Delta$. Thus, firm 1's profit with tying is $\widetilde{\Pi}_{1}^{*}=\alpha+\left(\frac{\beta_{a}}{2}\right)^{2}+(\eta-\Delta)$ while its profit without tying is $\Pi_{1}^{*}=\max \left\{\frac{1}{4}(1+\alpha)^{2}, \alpha\right\}$. When $\alpha \geq 1$, firm 1 serves all consumers in the tying market regardless of tying. Therefore, tying is profitable as it increases the profit from the tying market from $\alpha$ to $\alpha+\eta-\Delta$ and generates the profit from the apps. By continuity, tying is profitable for $\alpha$ close to one and we have the following result.

Proposition 7. When the tipping equilibrium prevails under tying, firm 1 has incentives to tie if $\alpha>\alpha^{*} \equiv 1-\sqrt{\left(\beta_{a}\right)^{2}+4(\eta-\Delta)}$.

Proof. When $\alpha \geq 1$, firm 1's profit without tying is $\alpha$. Since $\frac{\beta_{c} \beta_{a}}{2} \geq \Delta$ in the tipping equilibrium, it immediately follows that tying is profitable when $\alpha \geq 1$. For $\alpha<1$, firm 1 's profit under tying is $\frac{1}{4}(1+\alpha)^{2}$. A simple comparison of firm 1's profits under each regime yields the result.

The proposition indicates that tying is more likely to be profitable for $\alpha$ high, $\beta_{c}$ high and $\beta_{a}$ high. Propositions 6 and 7 , taken together, yield the following Corollary.

Corollary 1. If $\eta \geq \Delta$ and $\alpha>\max \left[\widehat{\alpha}, \alpha^{*}\right]$ (where $\max \left[\widehat{\alpha}, \alpha^{*}\right]<1$ ), firm 1 engages in tying and the resulting equilibrium is a tipping equilibrium in which firm 2 is foreclosed from the market. 
We point out the difference the introduction of intergroup network effects creates with respect to the result in the previous section. In section 4 , for a given $\beta$, tying becomes unprofitable at some point as $\alpha$ increases. The reason is that without network effects, the rival firm can always induce some marginal consumers in market $A$ to buy product $B$ when tying takes place. As a result, tying entails greater loss as $\alpha$ increases. However, this effect can disappear in the model with intergroup network effects if tying induces a tipping equilibrium, which is more likely when $\alpha$ is high.

\subsubsection{Interior Equilibrium}

Due to the conflicting effects of $\alpha$, the effects of tying on the tying firm's profits can be subtle in the interior equilibrium. As explained earlier, a higher $\alpha$ induces the tying firm to price more aggressively in the consumer market, providing more surplus to inframarginal consumers of $A$, which can be used to compete against firm 2 in market $B$ when tying takes place. In the interior equilibrium, however, capturing a certain share of market $B$ comes at the expense of the share of market $A$, which can be very costly when $\alpha$ is very high. We thus can show that tying cannot be a profitable strategy if $\alpha$ is sufficiently large as in Section 4.

In the case of an interior equilibrium, let us focus on the case in which $\widetilde{P}^{*}=0$. This holds either if $\Psi<0$ and $\eta<\Delta$ (see Lemma 7(ii) in Appendix) or if $\Psi \geq 0$ but $n_{1}^{c *} \Psi$ is bounded above by $\alpha$ (i.e. (6) is satisfied) (see Lemma 9(i) in Appendix). In both cases, firm 1's market share under tying is independent of $\alpha$ and is given by

$$
n_{1}^{c *}=\left\{\begin{array}{c}
1-\frac{\Delta-\eta}{(1-\eta)} \text { if } \Psi<0 \\
1-\frac{\Delta-\eta}{\Psi+(1-\eta)} \text { if } \Psi \geq 0 .
\end{array}\right.
$$

Define the difference between firm 1's profit under tying and firm 1's profit without tying as follows

$$
\Delta \Pi(\alpha) \equiv\left\{\begin{array}{cc}
n_{1}^{c *}\left(\alpha+\frac{\left(\beta_{a}\right)^{2}}{4} n_{1}^{c *}\right)-\left(\frac{1+\alpha}{2}\right)^{2}, & \text { if } \alpha \in[0,1] \\
n_{1}^{c *}\left(\alpha+\frac{\left(\beta_{a}\right)^{2}}{4} n_{1}^{c *}\right)-\alpha, & \text { if } \alpha>1 .
\end{array}\right.
$$

Suppose that $n_{1}^{c *}$ is close enough to one that $\Delta \Pi(1)>0$. Note first that $\Delta \Pi(\alpha)$ is concave

for $\alpha \in[0,1]$. For $\alpha>1$, as $\Delta \Pi(\alpha)$ linearly decreases, there exists $\bar{\alpha}=\frac{\left(\beta_{a}\right)^{2}}{4} n_{1}^{c *} /\left(1-n_{1}^{c *}\right)$ at which $\Delta \Pi(\bar{\alpha})=0$. We below distinguish the case of $\Delta \Pi(0) \geq 0$ from $\Delta \Pi(0)<0$. Suppose $\Delta \Pi(0) \geq 0$. Then, tying is strictly profitable for any $\alpha \in(0, \bar{\alpha})$. If $\Delta \Pi(0)<0$, there exists some $\underline{\alpha} \in(0,1)$ at which $\Delta \Pi(\underline{\alpha})=0$. Hence, tying is profitable for any $\alpha \in(\underline{\alpha}, \bar{\alpha})$. 
As $\bar{\alpha}$ tends to $\infty$ when $n_{1}^{c *}$ goes to one, the result obtained when $\Delta \Pi(0)<0$ extends the result on the incentive to tie in the tipping equilibrium, described in Proposition 7 , to an interior market share.

\subsection{Welfare Analysis}

We now analyze welfare implications of tying. First consider the case where tying leads to tipping. If $\alpha>1$, all consumers in market $\mathrm{A}$ were served before tying. There is thus no market expansion effect in this case. The only effect is that consumers switch from firm 2's product to firm 1's product, which is inferior. Thus, tying unambiguously reduces welfare in this case, with the welfare loss being $\Delta$. If $\alpha<1$, but tying induces tipping, there is a positive market expansion effect in market $A$. The welfare gain from this market expansion can be expressed as

$$
E=\int_{0}^{\frac{1-\alpha}{2}} u d u+\left(\frac{1-\alpha}{2}\right) \alpha=\frac{(1+3 \alpha)(1-\alpha)}{8}
$$

This welfare gain needs to be measured against the loss in welfare in market $B$, which is $\Delta$. Tying can be welfare reducing if $E<\Delta$. $E$ is highest at $1 / 6$ when $\alpha=1 / 3$. Therefore, a sufficient condition that tying reduces welfare is $\Delta>1 / 6$ if tying induces tipping towards the bundled product.

If tying does not lead to tipping, there is an additional type of welfare loss due to a fragmented market structure which does not fully exploit network benefits.

We can also analyze the effects of tying on consumer surplus. For instance, suppose that $\alpha>1$ and tying leads to tipping. If $\widetilde{P}^{*}=0$, consumers are indifferent between tying and no tying. However, if $\widetilde{P}^{*}>0$, consumers lose from tying. Without tying, each consumer enjoys $\frac{\left(\beta_{a}\right)^{2}}{2}$ of surplus from firm 2 in market $B$ because of price competition in market $B$. Tying removes the level playing field and allows the tying firm to extract the surplus from network effects.

\subsection{Extension: No Constraint on Pricing}

The analysis in this section has maintained the assumption of the non-negative price constraint to be consistent with the rest of the paper. However, the leverage mechanism of this section is essentially based on intergroup network effects and remains valid even if we assume away the constraint on pricing. We illustrate the logic behind this point by 
focusing on the incentive to tie when $\alpha \geq 1$ (hence, the monopoly price is zero in market $A$ ). In particular, we show that when $\alpha \geq 1$, firm 1 has incentives to tie if tying induces market $B$ to tip in favor of the tying firm.

Note first that without tying, firm 1 makes a profit equal to $\alpha$ only from market $A$. In market $B$, the equilibrium prices on the consumer side are given by $p_{1}^{c}=-\frac{\left(\beta_{a}\right)^{2}}{4}, p_{2}^{c}=$ $\Delta-\frac{\left(\beta_{a}\right)^{2}}{4}$ in the absence of the non-negative price constraint. In equilibrium, all consumers coordinate on firm 2. As firm 2 subsidizes consumers with the revenues it can obtain from the other side, its profit is equal to $\Delta$.

Consider now tying by firm 1 . Let us focus on the tipping equilibrium. A pair of prices $\left(\widetilde{P}^{*}, \widetilde{p}_{2}=0\right)$ leads to tipping towards firm 1 if and only if (i) firm 1's consumer market share is equal to one at those prices (i.e., $\widetilde{P}^{*} \leq \eta-\Delta$ ) (ii) no firm has an incentive to deviate. Regarding (ii), the Appendix shows that each firm's profit as a function of its price on the consumer side at stage 1 is convex if and only if $2 \eta+\frac{1}{4}\left(\beta_{a}\right)^{2} \geq 1$, and concave otherwise. Consider first the convex case. Then, the relevant deviation for firm 2 is to corner the market, which requires it to choose $\widetilde{p}_{2}^{d}(<0)$ such that

$$
\frac{\Delta+\widetilde{P}^{*}-\widetilde{p}_{2}^{d}-\eta}{\left(1-\beta_{c} \beta_{a}\right)}=1
$$

Then, platform 2's profit is $\widetilde{\pi}_{2}^{d}=\widetilde{p}_{2}^{d}+\frac{\left(\beta_{a}\right)^{2}}{4}=\Delta+\widetilde{P}^{*}-(1-\eta)+\frac{\left(\beta_{a}\right)^{2}}{4}$. Therefore, the deviation by firm 2 is not profitable and tipping towards platform 1 is an equilibrium if

$$
\widetilde{P}^{*} \leq \min \left\{\eta-\Delta, 1-\eta-\frac{\left(\beta_{a}\right)^{2}}{4}-\Delta\right\}=1-\eta-\frac{\left(\beta_{a}\right)^{2}}{4}-\Delta
$$

where the equality comes from $1-2 \eta-\frac{1}{4}\left(\beta_{a}\right)^{2} \leq 0$. As the profit is convex, firm 1 has no incentive to deviate either as long as its profit is positive. Platform 1's profit under tying is $\widetilde{\Pi}_{1}^{*}=\widetilde{P}^{*}+\alpha+\frac{\left(\beta_{a}\right)^{2}}{4}=1-\eta-\Delta+\alpha$. This implies that firm 1 has incentives to tie if $1-\eta-\Delta>0$, which holds under our maintained assumption that $1 / 2>\max \{\eta, \Delta\}$.

Consider now the concave case. Then, firm 2 has no incentive to deviate if the firstorder derivative of its profit $\widetilde{\pi}_{2}$ with respect to $\widetilde{p}_{2}$ is zero or positive at $\widetilde{p}_{2}=0$. In the Appendix, we show

$$
\frac{\partial \widetilde{\pi}_{2}}{\widetilde{p}_{2}}=-\frac{1}{1-\beta_{c} \beta_{a}}\left[\widetilde{p}_{2}-n_{2}^{c} \Psi\right]
$$

where $\Psi=1-\beta_{c} \beta_{a}-\frac{\left(\beta_{a}\right)^{2}}{2}$. Hence, the derivative is zero at $\widetilde{p}_{2}=0$ since $n_{2}^{c}=0$. 
Symmetrically, firm 1 has no incentive to deviate if the first-order derivative of its profit $\widetilde{\Pi}_{1}$ with respect to $\widetilde{P}$ is zero or negative at $\widetilde{P}=\widetilde{P}^{*}$. In the Appendix, we show

$$
\frac{\partial \widetilde{\Pi}_{1}}{\partial \widetilde{P}}=-\frac{1}{1-\beta_{c} \beta_{a}}\left[\widetilde{P}+\alpha-n_{1}^{c} \Psi\right]
$$

Firm 1 has no incentive to deviate if $\widetilde{P}^{*} \geq \Psi-\alpha$. Therefore, we have a tipping equilibrium towards firm 1 if $\eta-\Delta \geq \Psi-\alpha$. In the equilibrium, firm 1 chooses $\widetilde{P}^{*}=\eta-\Delta$ and its profit under tying is $\widetilde{\Pi}_{1}^{*}=\widetilde{P}^{*}+\alpha+\frac{\left(\beta_{a}\right)^{2}}{4}=\eta-\Delta+\alpha+\frac{\left(\beta_{a}\right)^{2}}{4}$. Firm 1 thus has incentives to tie if $\eta+\frac{\left(\beta_{a}\right)^{2}}{4}>\Delta$. We can easily verify that $\eta+\frac{\left(\beta_{a}\right)^{2}}{4}>\Delta$ implies $\eta-\Delta \geq \Psi-\alpha$ because $\alpha-\Psi>\frac{\left(\beta_{a}\right)^{2}}{4}$ holds from $\alpha \geq 1$.

In summary, we can conclude that when $\alpha \geq 1$, firm 1 has incentives to tie if tying induces a tipping equilibrium and $\Delta$ is small enough to satisfy $\eta+\frac{\left(\beta_{a}\right)^{2}}{4}>\Delta$.

\subsection{Application to the Google Android Case}

In the Google Android case, the EC issued a statement of objections on April 20, 2016, informing Google of its view that "the company has, in breach of EU antitrust rules, abused its dominant position by imposing restrictions on Android device manufacturers and mobile network operators." ${ }^{44}$ Even though Google's Android operating system for mobile devices is supposed to be "open," Google effectively implements bundling of its apps through Android's Mobile Application Distribution Agreements (MADA) contracts that force manufacturers to include them and their respective terms in an all-or-nothing fashion. ${ }^{45}$ According to MADA contracts, Android device manufacturers must preinstall all or none of Google apps, depriving them of the ability to mix and match Google apps considered essential with other third-party apps which may be superior to some of the listed Google apps. Even though they are allowed to preinstall competing apps in addition to the listed Google apps with similar functionalities, they are reluctant to do so because of the limited screen space available on devices and potential user confusion. ${ }^{46}$ In addition, Google requires its apps to be the default in key app categories such as search

\footnotetext{
${ }^{44}$ See the European Commission Press Release entitled "Antitrust: Commission sends Statement of Objections to Google on Android operating system and applications," available at http://europa.eu/rapid/press-release_IP-16-1492_en.htm

45 "Devices may only be distributed if all Google Applications [listed elsewhere in the agreement] ... are pre-installed on the Device." See section 2.1 of the MADA between Google and HTC.

${ }^{46}$ Other considerations that limit pre-installation of competing apps include their impacts on RAM, battery life, and limited storage space.
} 
and location and be placed in prominent positions on the screen. ${ }^{47}$ As a result, the potential for installing multiple apps (i.e., multihoming) to mitigate the effects of tying is somewhat limited (Edelman, 2015). The EC's analysis in relation to the investigation of Google also indicates that "consumers rarely download applications that would provide the same functionality as an app that is already pre-installed (unless the pre-installed app is of particularly poor quality)." 48

For the sake of concreteness and simplicity, consider Google Play as the (monopolized) tying good (as there are no effective competitors) and Google search as the tied good (for which there are some competitors such as Bing). According to Etro and Caffarra (2017), the value of the tying product can be interpreted as the difference in quality between normal Android devices with the GP/GPS suite and "forked" Android devices that lack Google Play, YouTube and other apps in the GP/GPS suite. The assumption of nonnegative prices is not appropriate in the Google application since app developers can make payments to OEMs to have their apps to be pre-installed, which effectively constitutes a negative price for consumers if the payments to OEMs are passed along to consumers.

We first note that Etro and Caffarra (2017) develop a sensible extension of our baseline model in Section 2.1 that closely approximates the facts of the Android case. ${ }^{49}$ Their main assumption is that Google is committed to charge zero price to Google Play (i.e., to the GP/GPS suite). ${ }^{50}$ This implies that Google has a "surplus slack" in the tying good market (due to its free availability), which can be leveraged to the tied good market via bundling. Although this mechanism is different from those explained in section 2, it is similar to the mechanism of tying in the complementary products case in section 2.2 since both mechanisms are based on "imperfect surplus extraction". In Etro and Caffarra (2017),

\footnotetext{
${ }^{47}$ For instance, the phone manufacturer must set "Google Search ... as the default search provider for all Web search access points." See MADA Section 3.4(4). The same requirement applies to Google's Network Location Provider service.

${ }^{48}$ See the European Commission - Fact Sheet entitled "Antitrust: Commission sends Statement of Objections to Google on Android operating system and applications,' released on April 20, 2016. Available at http://europa.eu/rapid/press-release_MEMO-16-1484_en.htm.

${ }^{49}$ See Etro and Caffara (2017) for more detailed discussion of the Android case and how they extend our model.

${ }^{50}$ As explained by Etro and Caffarra (2017), there are multiple reasons for Google to provide its GP/GPS suite without any charges. First, the GP/GPS suite needed to be offered for free for strategic reasons such as market penetration and building an installed base of consumers when its Android mobile operating system was first introduced in 2007 as there were other competing alternatives such as Symbian and Windows Mobile. In addition, application stores such as Google Play themselves can be considered as a two-sided market that can generate revenues from the other side by receiving a percentage of revenues from application developers.
} 
imperfect surplus extraction is simply due to Google's zero price commitment. Moreover, they show that their result is robust to relaxing the zero price assumption when consumers are heterogenous in the value they obtain from Google Play.

We can also apply the model of the inter-group network effects of this section to the Google Android case because network effects are important in the search market. A search engine with a larger consumer base is valued more by advertisers because they can reach a larger number of consumers. A search engine with a larger number of advertisers participating in keyword auctions should be valued more by consumers because sponsored search results become more relevant. These standard cross-group network effects are reinforced by intertemporal indirect network effect as more search log data means better search results. ${ }^{51}$ He et al. (2017), for instance, find important scale effects of data on search engine performance due to learning from historical queries. As learning tends to slow down with each additional data point, scale effects are more important for rarer queries which account for the majority of queries. According to He et al. (2017), in 2007 Google estimated that $20-25 \%$ of the queries they see each day are unique when compared to the queries from the last month. ${ }^{52}$

Note that the main insight of this section is robust to allowing for negative prices (as shown in subsection 5.5). For the application to the Google Android case, we can consider (i) competition between Google and a rival search engine for an exclusive preinstallation, and (ii) competitive OEMs who pass through consumer side app prices to handset prices. In the absence of tying, there is a tipping equilibrium to the handsets with the rival search engine preinstalled (as we assume that the rival search engine is superior to Google search) with the price of $c+p_{1}^{A}+p_{2}^{c}$, where $c$ is the cost of a handset. By tying Google Play with Google search, Google denies scale to the rival search engine. In particular when the extra revenues generated by Google Play (represented by $\alpha$ ) are sufficiently large, Google may find it optimal to charge a very aggressive price to the bundle of Google Play and Google search such that the market tips to the handsets which preinstall Google Play and Google search with the price of $c+\widetilde{P} \cdot{ }^{53}$

\footnotetext{
${ }^{51}$ See Argenton and Prüfer (2012) for an analysis of search engine competition with indirect network effects based on search logs.

${ }^{52}$ In addition to direct effects of scale related to the volume of historical data for a target query, there are also indirect effects of scale as search engine algorithms can construct a knowledge graph to identify related queries that can supplement direct query data.

${ }^{53}$ For apps and in-app products offered through Google Play, the transaction fee is equivalent to $30 \%$ of the price.
} 


\section{Concluding Remarks}

In this paper, we have developed a leverage theory of tying in two-sided markets. The basic premise of our theory is that the optimal pricing and competition strategies in a two-sided market often lead to below-cost pricing on one side of the market whose loss is often recouped on the other side. When the below-cost pricing is constrained by the non-negative price constraint, competition is relaxed and supra-competitive profits can be created. A monopolist in another market can extract this surplus via a tying arrangement which effectively allows the tying firm to engage in negative pricing. Furthermore, as the competing firm in the tied two-sided market is constrained by non-negative pricing, its response to tying cannot be so aggressive, which in turn makes tying even more profitable. We also demonstrated that this mechanism can also be applied to other market contexts such as dynamic competition with direct network effects and switching costs.

Our analysis has focused on the effects of tying on short-run price competition and their implications on consumer surplus and welfare. In our baseline model with homogenous consumers, for instance, tying is welfare-reducing because it induces inefficient switching to the inferior product of the tying firm in the tied market. Nonetheless, consumers are not worse off because they are compensated for the consumption of the inferior product by the tying firm. However, if we consider rival firms' incentives to develop new products in the tied market, we may find further harm in consumer welfare because more innovative products may not be introduced by the rival firms due to the lack of market access. However, we also point out that there could be many efficient reasons to engage in tying such as integration of different apps which enables the tying firm to provide better and

seamless services to consumers. Antitrust investigations should weigh these potential efficiencies against the potential harm identified in this paper. 


\section{References}

[1] Adams, Walter, J. and Janet L. Yellen, "Commodity Bundling and the Burden of Monopoly," Quarterly Journal of Economics, 1976, 90 (Aug.), pp. 475-498.

[2] Amelio, Andrea and Bruno Jullien, "Tying and Freebie in Two-Sided Markets," International Journal of Industrial Organization, 2012, pp. 436-446.

[3] Armstrong, Mark, "Competition in Two-Sided Markets," Rand Journal of Economics, 2006, 37 (3), pp. 668-691.

[4] Armstrong, Mark and Julian Wright, "Two-Sided Markets, Competitive Bottlenecks and Exclusive Contracts," Economic Theory, 2007, 32, pp. 353-380.

[5] Areeda, Phillip E., Louis Kaplow, and Aaron S. Edlin, Antitrust Analysis: Problems, Text, and Cases, 7th Edition, Aspen Casebook, 2013.

[6] Argenton, Cédric and Prüfer Jens, "Search Engine Competition With Network Externalities," Journal of Competition Law and Economics, 2012, 8 (1), pp. 73-105.

[7] Ayres, Ian and Barry Nalebuff, "Going Soft on Microsoft? The EU's Antitrust Case and Remedy," Economists' Voice, vol. 2, issue 2, art. 4, 2005.

[8] Bork, Robert, "Vertical Integration and the Sherman Act: The Legal History of an Economic Misconception," University of Chicago Law Review, 1954, 22 (1), pp. $157-201$

[9] Bowman, Ward S. Jr., "Tying Arrangements and the Leverage Problem," Yale Law Journal, 1957, 67, pp. 19-36

[10] Caillaud, Bernard and Bruno Jullien, "Chicken and Egg: Competition among Intermediation Service Providers," Rand Journal of Economics, Summer 2003, pp. 309-328.

[11] Carbajo, Jose, David De Meza, and Daniel J. Seidman, "A Strategic Motivation for Commodity Bundling," Journal of Industrial Economics, March 1990, 38, pp. 283-298.

[12] Carlton, Dennis, W. and Michael Waldman, "The Strategic Use of Tying to Preserve and Create Market Power in Evolving Industries," Rand Journal of Economics, Summer 2002, pp. 194-220.

[13] Carlton, Dennis, W. and Michael Waldman, "Upgrades, Switching Costs and the Leverage Theory of Tying," Economic Journal, June 2012, pp. 675-706. 
[14] Chee, Foo Yun, "EU Hits Google with Second Antitrust Charge," Reuters, April 20, 2016, available at http://www.reuters.com/article/us-eu-google-antitrustidUSKCNOXHOVX.

[15] Chen, Yongmin, "Equilibrium product bundling," Journal of Business, 1997, 70, pp. 85-103.

[16] Choi, Jay Pil, "Tying in Two-Sided Markets with Multi-Homing," Journal of Industrial Economics, 2010, 58 (3), pp. 607-626

[17] Choi, Jay Pil and Christodoulos Stefanadis, "Tying, Investment and the Dynamic Leverage Theory," Rand Journal of Economics, Spring 2001, pp. 52-71.

[18] de Cornière, Alexandre and Greg Taylor, "Applicatioin Bundling in System Markets," unpublished manuscript, June 2017.

[19] Director, Aaron and Edward H. Levi, "Law and the Future: Trade Regulation," Northwestern University Law Review, 1956, 51, pp. 281-296

[20] Edelman, Benjamin, "Does Google Leverage Market Power Through Tying and Bundling?," Journal of Competition Law \& Economics, 2015, pp.365-400.

[21] Edelman, Benjamin and Damien Geradin, "Android and Competition Law: Exploring and Assessing Google's Practice in Mobile," October 2016, unpublished manuscript, available at http://www.benedelman.org/publications/google-mobile-201610-24.pdf.

[22] Etro, Federico and Cristina Caffarra, "On the Economics of the Android Case," European Competition Journal, 2017, pp. 282-313.

[23] Farrell, Joseph and Nancy T. Gallini, "Second-Sourcing as a Commitment: Monopoly Incentives to Attract Competition," Quarterly Journal of Economics, 1988, pp. 673694.

[24] Fumagalli, Chiara, "A Note on the Google (comparison shopping) Case," unpublished manuscript, 2017.

[25] Fumagalli, Chiara, Massimo Motta, and Claudio Calcagno, Exclusionary Practices: The Economics of Monopolisation and Abuse of Dominance, Cambrige University Press, 2018.

[26] Greenlee, Patrick, David Reitman, and David S. Sibley, "An Antitrust Analysis of Bundled Loyalty Discounts," International Journal of Industrial Organization, 2008, pp. 1132-1152. 
[27] He, Di, Aadharsh Kannan, Tie-Yan Liu, R. Preston McAfee, Tao Qin, and Justin M. Rao, "Scale Effects in Web Search," In: R. Devanur N., Lu P. (eds) Web and Internet Economics. WINE 2017. Lecture Notes in Computer Science, vol 10660. Springer, Cham.

[28] Hurkens, Sjaak, Doh-Shin Jeon, and Domenico Menicucci, "Dominance and Competitive Bundling," American Economic Journal: Microeconomics, forthcoming.

[29] Iacobucci, Edward M., "Tying in Two-Sided Markets, with Application to Google," unpublished manuscript, September 2014.

[30] Iacobucci, Edward and Francesco Ducci, "The Google Search Case in Europe: Tying and the Single Monopoly Profit Theorem in Two-Sided Markets," European Journal of Law and Economics, 2019, 47, pp. 15-42.

[31] Jeon, Doh-Shin and Domenico Menicucci, "Bundling Electronic Journals and Competition among Publishers," Journal of the European Economic Association, 2006,.4 (5), pp. 1038-83.

[32] Jeon, Doh-Shin and Domenico Menicucci, "Bundling and Competition for Slots", American Economic Review, 2012, 102, pp. 1957-1985.

[33] Katz, Michael and Carl Shapiro, "Technology Adoption in the Presence of Network Externalities," Journal of Political Economy, 1986, 94, pp.822-841.

[34] Klemperer, Paul, "Competition when Consumers have Switching Costs," Review of Economic Studies, 1995, 62, pp. 515-539.

[35] McAfee. R. Preston, John McMillan, and Michael D. Whinston, "Multiproduct Monopoly, Commodity Bundling, and Correlation of Values," Quarterly Journal of Economics, 1989, 104 (May), pp. 371-384.

[36] Newman, John M., "Antitrust in Zero-Price Markets: Foundations," The University of Pennsylvania Law Review, 2015, pp. 149-206.

[37] Newman, John M., "Antitrust in Zero-Price Markets: Applications," Washington University Law Review, 2016, 94 (1).

[38] Posner, Richard A., Antitrust Law: An Economic Perspective. Chicago: University of Chicago Press, 1976.

[39] Posner, Richard A., "The Chicago School of Antitrust Analysis," The University of Pennsylvania Law Review, 1979, 127, pp 925-948

[40] Rochet, Jean-Charles and Jean Tirole, "Two-Sided Markets: A Progress Report," Rand Journal of Economics, 2006, pp. 645-667. 
[41] Stigler, George, J., "United States v. Loew's Inc.: A Note on Block-Booking," The Supreme Court Review, 1963, pp. 152-157.

[42] Waldman, Michael, "A New Perspective on Planned Obsolescence, " Quarterly Journal of Economics, 1993, 108, pp. 273-284.

[43] Whinston, Michael D., 'Tying, Foreclosure and Exclusion,' American Economic Review, 1990, 80, pp. 837-859. 


\section{Appendix}

\section{Analysis with Positive Production Costs}

We show that our analysis is robust to the introduction of positive production costs as long as production costs are not too high (as in the case of digital goods such as software and apps). To see this, let us assume that the constant production costs for products $A$ and $B$ are respectively given by $c_{A}$ and $c_{B}$. Consider the case where market $B$ is two-sided while market $A$ is one-sided (i.e., $\alpha=0$ and $\beta>0$ ). In the absence of tying, firm 1 charges a price of $p_{1}^{B}=\max \left[0, c_{B}-\beta\right]$ and firm 2 will set the price of $p_{2}^{B}=\max \left[0, c_{B}-\beta\right]+\Delta$ with the non-negative price constraint. Firm 1 's profit in market $B$ is zero while firm 2 ' profit is given by $\pi_{2}^{B}=\max \left[0, c_{B}-\beta\right]+\Delta+\beta-c_{B}=\max \left[\beta-c_{B}, 0\right]+\Delta$. Firm 1's overall profit is given by $\Pi_{1}=\pi_{1}^{A}+\pi_{1}^{B}=\left(u-c_{A}\right)+0=u-c_{A}$.

Now suppose that firm 1 ties its monopolized product with product $B$ on the consumer side. The maximum bundle price that enables the tying firm to make sales is given by $\widetilde{P}=u-\Delta+\widetilde{p}_{2}$. As the lowest price firm 2 is willing to charge is given by $\widetilde{p}_{2}=\max \left[0, c_{B}-\beta\right]$, the tying firm's profit now becomes

$$
\begin{aligned}
\widetilde{\Pi}_{1} & =\widetilde{P}+\beta-\left(c_{A}+c_{B}\right)=\left(u-\Delta+\max \left[0, c_{B}-\beta\right]\right)+\beta-\left(c_{A}+c_{B}\right) \\
& =\left(u-c_{A}\right)-\Delta+\max \left[\beta-c_{B}, 0\right] .
\end{aligned}
$$

Hence, tying is profitable if $\beta>c_{B}+\Delta$, or production costs for the tied product is not too high, i.e., $c_{B}<(\beta-\Delta)$.

\section{Proof of Proposition 3}

We show that no firm has incentives to deviate at the putative equilibrium prices of $\widetilde{P}=u-\Delta$ and $\widetilde{p}_{2}=0$. When consumers are indifferent between buying the bundle only and buying firm 2's product only, we break the tie in favor of the bundle to avoid the open set problem: this is because firm 1 can decrease its price by $\varepsilon>0$, but firm 2 cannot because it is constrained by non-negative pricing. At these prices, a consumer's payoff is $v_{2}$ if he single-homes and buys only the bundle while his payoff is $v_{2}+\Delta-m$ if he multihomes. Therefore, only those consumers with $m \leq \Delta$ multihome in equilibrium.

Consider first the deviation of firm 2 to $\widetilde{p}_{2}>0$. A deviation to $\widetilde{p}_{2}>\Delta$ is obviously not optimal as firm 2 would have no demand. If $\widetilde{p}_{2} \leq \Delta$, the marginal consumer type 
who is indifferent between multihoming and not is given by $m^{*}=\Delta-\widetilde{p}_{2}$. With this deviation, firm 2's profit is given by

$$
\pi_{2}\left(\widetilde{p}_{2} ; \widetilde{P}=u-\Delta\right)=\left(\widetilde{p}_{2}+\beta\right) G\left(\Delta-\widetilde{p}_{2}\right)
$$

The first-order derivative is

$$
\frac{\partial \pi_{2}}{\partial \widetilde{p}_{2}}=G\left(\Delta-\widetilde{p}_{2}\right)-\left(\widetilde{p}_{2}+\beta\right) g\left(\Delta-\widetilde{p}_{2}\right) \leq 0
$$

when it is evaluated at $\widetilde{p}_{2}=0$ with the assumption of $G(\Delta) / g(\Delta) \leq \beta$. The log-concavity

of $g$ guarantees that $\frac{\partial \pi_{2}}{\partial \widetilde{p}_{2}}<0$ when evaluated at all positive $\widetilde{p}_{2}$. Therefore, there is no profitable deviation for firm 2 .

Consider now a deviation by firm 1 . Its equilibrium profit from $\widetilde{P}=u-\Delta$ is $(u-\Delta)+$ $[1-G(\Delta)] \beta$. It has no incentive to decrease its price from the equilibrium price since it sells the bundle to all consumers. Consider a deviation to $\widetilde{P}>u-\Delta$. Then, all consumers prefer buying firm 2's product to buying the bundle. If a consumer multi-homes and also buys the bundle, his payoff increases by $(u-\widetilde{P}-m)$. Therefore, only consumers whose cost of multi-homing is less than $(u-\widetilde{P})$ multi-home. Firm 1's profit upon the deviation is $\widetilde{P} G(u-\widetilde{P})$, which cannot be larger than the profit under no tying, $u$. Hence, if firm 1 has an incentive to tie, such deviation is never profitable. Firm 1 has incentives to tie if $\widetilde{\Pi}_{1}=(u-\Delta)+[1-G(\Delta)] \beta \geq u=\Pi_{1}$, that is, if $[1-G(\Delta)] \beta>\Delta$.

\section{Proof of Lemma 1}

(i) If $\widetilde{P} \in\left[\widetilde{p}_{2}-\Delta, 1+\widetilde{p}_{2}-\Delta\right]$, firm 1's profit is

$$
\Pi_{1}\left(\widetilde{P}, \widetilde{p}_{2}\right)=\left(1-\left[\left(\widetilde{P}-\widetilde{p}_{2}\right)+\Delta\right]\right)(\widetilde{P}+\alpha+\beta)
$$

The first-order condition with respect to $\widetilde{P}$ is equivalent to

$$
\widetilde{P}=\frac{(1-\Delta)-(\alpha+\beta)+\widetilde{p}_{2}}{2}
$$

For this to be the optimal, the condition $\widetilde{P}=\frac{(1-\Delta)-(\alpha+\beta)+\widetilde{p}_{2}}{2} \geq \max \left\{0, \widetilde{p}_{2}-\Delta\right\}$ needs to be satisfied.

When $0 \leq \widetilde{P}<\widetilde{p}_{2}-\Delta$, firm 1's profit is 


$$
\Pi_{1}\left(\widetilde{P}, \widetilde{p}_{2}\right)=(\widetilde{P}+\alpha+\beta)
$$

Hence, it is optimal to choose $\widetilde{P}=\max \left\{0, \widetilde{p}_{2}-\Delta\right\}$ given the non-negative price constraint.

Therefore, the best response is $\widetilde{P}=\frac{(1-\Delta)-(\alpha+\beta)+\widetilde{p}_{2}}{2}$ for $\Delta+[1-(\alpha+\beta)] \geq \widetilde{p}_{2}>$ $\Delta-[1-(\alpha+\beta)]$. If $1 \leq \alpha+\beta$ or for $\widetilde{p}_{2} \notin[\Delta+[1-(\alpha+\beta)], \Delta-[1-(\alpha+\beta)]$, it is optimal to choose $\widetilde{P}=\max \left\{0, \widetilde{p}_{2}-\Delta\right\}$.

(ii) Firm 2's profit is zero if $0 \leq \widetilde{P}<\widetilde{p}_{2}-\Delta$. If $\widetilde{P} \geq \widetilde{p}_{2}-\Delta$, its profit is

$$
\pi_{2}\left(\widetilde{P}, \widetilde{p}_{2}\right)=\left[\left(\widetilde{P}-\widetilde{p}_{2}\right)+\Delta\right]\left(\widetilde{p}_{2}+\beta\right)
$$

The first-order condition with respect to $\widetilde{p}_{2}$ yields

$$
\left[\left(\widetilde{P}-\widetilde{p}_{2}\right)+\Delta\right]-\left(\widetilde{p}_{2}+\beta\right)=0
$$

which can be rewritten as

$$
\widetilde{p}_{2}=\frac{(\Delta-\beta)+\widetilde{P}}{2} .
$$

For this to be the optimal, the condition for $\widetilde{p}_{2}=\frac{(\Delta-\beta)+\widetilde{P}}{2} \leq \widetilde{P}+\Delta$ needs to be satisfied, i.e., $\widetilde{P} \geq-(\Delta+\beta)$, which holds always. We can thus write the best response of firm 2 as

$$
B R_{2}(\widetilde{P})=\max \left[\frac{(\Delta-\beta)+\widetilde{P}}{2}, 0\right]
$$

\section{Proof of Lemma 2}

It is omitted as it is straightforward from the explanations in the main text.

\section{Proof of Lemma 3}

In this case, it can be easily shown that $\widetilde{P}^{\circ}>\widetilde{p}_{2}{ }^{\circ}$. Thus, the non-negative price constraint is binding first for the rival firm's price under tying. We thus have

$$
\widetilde{P}^{*}=\frac{(1-\Delta)-(\alpha+\beta)}{2}, \widetilde{p}_{2}^{*}=0
$$

Firm 1 and firm 2's demands are respectively given by

$$
\widetilde{D}_{1}=\frac{(1-\Delta)+(\alpha+\beta)}{2}, \widetilde{d}_{2}=\frac{(1+\Delta)-(\alpha+\beta)}{2} .
$$


The corresponding profits are given by

$$
\widetilde{\Pi}_{1}=\left[\frac{(1-\Delta)+(\alpha+\beta)}{2}\right]^{2}, \widetilde{\pi}_{2}=\beta\left[\frac{(1+\Delta)-(\alpha+\beta)}{2}\right] .
$$

Since $\alpha<1-2 \Delta$ in the case we consider, firm 1's profit under no tying is $\Pi_{1}=\left(\frac{1+\alpha}{2}\right)^{2}$. Since $\beta>\Delta$ in this case, we have $\widetilde{\Pi}_{1}>\Pi_{1}$, that is, tying is profitable for the tying firm. In contrast, tying reduces the rival firm's profit. To see this, note that the rival firm's profit in the absence of tying is $\pi_{2}=\beta+\Delta>\beta>\beta\left[\frac{(1+\Delta)-(\alpha+\beta)}{2}\right]=\widetilde{\pi}_{2}$ because $(1+\Delta)-(\alpha+\beta)<2$ as $\beta>\Delta$.

\section{Proof of Lemma 4}

It is omitted as the proof of (i) and (ii) is provided in the main text and the proof of (iii) is straightforward.

\section{Proof of Lemma 5}

In this case, it can easily be shown that $\widetilde{P}^{\circ}<\widetilde{p}_{2}{ }^{\circ}$. Thus, the non-negative price constraint is binding first for the tying firm We thus have

$$
\widetilde{P}^{*}=0, \widetilde{p}_{2}^{*}=\frac{\Delta-\beta}{2}
$$

Firm 1 and firm 2's demands are respectively given by

$$
\widetilde{D}_{1}=1-\frac{\Delta+\beta}{2}, \widetilde{d}_{2}=\frac{\Delta+\beta}{2} .
$$

The corresponding profits are given by

$$
\widetilde{\Pi}_{1}=(\alpha+\beta)\left[1-\frac{\Delta+\beta}{2}\right], \widetilde{\pi}_{2}=\left[\frac{\Delta+\beta}{2}\right]^{2} .
$$

We need to show that

$$
\widetilde{\Pi}_{1}=(\alpha+\beta)\left[1-\frac{\Delta+\beta}{2}\right]<\left\{\begin{array}{c}
\left(\frac{1+\alpha}{2}\right)^{2} \text { if } \alpha<1 \\
\alpha \text { if } \alpha>1
\end{array}\right.
$$


For $\alpha<1$,we use the following fact

$$
\left(\frac{x+y}{2}\right)^{2} \geq x y \text { for any } x \text { and } y
$$

Let $x=\alpha+\beta$ and $y=1-\frac{\Delta+\beta}{2}$. Then, we have

$$
(\alpha+\beta)\left[1-\frac{\Delta+\beta}{2}\right]<\left(\frac{2+2 \alpha+\beta-\Delta}{4}\right)^{2} .
$$

Since $\beta<\Delta$ in this case, we have $\left(\frac{2+2 \alpha+\beta-\Delta}{4}\right)^{2}<\left(\frac{1+\alpha}{2}\right)^{2}$. Therefore, $\widetilde{\Pi}_{1}=(\alpha+$ $\beta)\left[1-\frac{\Delta+\beta}{2}\right]<\left(\frac{1+\alpha}{2}\right)^{2}=\Pi_{1}$ if $\alpha<1$.

For $\alpha>1$, tying is profitable only when $(\alpha+\beta)\left[1-\frac{\Delta+\beta}{2}\right]>\alpha$. This condition can be rewritten as

$$
\Delta<\frac{2 \beta}{\alpha+\beta}-\beta
$$

Since $\beta<\Delta$, the condition above can be satisfied only when $\beta<\frac{2 \beta}{\alpha+\beta}-\beta$, or $(\alpha+\beta)<1$, which is impossible because $\alpha>1$. Therefore, tying cannot be profitable for $\alpha>1$, either.

Tying obviously hurts firm 2 as tying reduces its price and market share.

\section{Proof of Lemma 6}

In market $A$, all consumers whose valuations satisfy $u \geq \frac{1-\alpha}{2}$ purchase product A. With tying, all consumers whose valuations satisfy $u \geq\left(1-\widetilde{D}_{1}\right)$ consume product A, where $\widetilde{D}_{1}$ denotes the bundle demand for firm 1 . Thus, for market $A$ to expand we need $\frac{1-\alpha}{2}>\left(1-\widetilde{D}_{1}\right)$. We can easily verify that this condition is equivalent to $\alpha<1-2 \Delta$ by checking all possible equilibrium price configurations with tying.

\section{Proof of Proposition 5}

- $\widetilde{P}^{*}=0, \widetilde{p}_{2}^{*}=0$

Consider a situation in which the post-tying equilibrium prices are zero $\left(\widetilde{P}^{*}=0, \widetilde{p}_{2}^{*}=\right.$ $0)$. Because $\widetilde{D}_{1}=1-\Delta$ in this case, the social welfare change with tying $(\Delta W)$ can be written as

$$
\Delta W=\int_{\Delta}^{\frac{1-\alpha}{2}}(u+\alpha) d u-(1-\Delta) \Delta
$$


We can easily see that if $\Delta$ is sufficiently small, then social welfare loss in market $B$ from tying is negligible. Thus, if $\beta$ is sufficiently large, firm 1 has incentives to capture market $B$ with tying, and tying can be socially beneficial as the market expansion effects in market $A$ outweigh social welfare loss in market $B .^{54}$

Consumer welfare in this case always increases because now both goods are provided for free.

- $\widetilde{P}^{*}>0, \widetilde{p}_{2}^{*}=0$

In this case, $\widetilde{D}_{1}=\frac{(1-\Delta)+(\alpha+\beta)}{2}$. By proceeding in a similar way as above, we can verify that if $\Delta$ is sufficiently small, tying can increase welfare. Otherwise, tying decreases welfare. It can also be shown that market $A$ always expands with tying as $\frac{1-\alpha}{2}>1-\widetilde{D}_{1}$ in this case.

Concerning consumer welfare, we can easily verify that $\widetilde{P}^{*}=\frac{(1-\Delta)-(\alpha+\beta)}{2}<p^{m}=\frac{1-\alpha}{2}$, i.e., the bundled product is even cheaper than the stand-alone $A$ product price before tying. As a result, consumers benefit from tying.

- $\widetilde{P}^{*}>0, \widetilde{p}_{2}^{*}>0$

In this case, $\widetilde{D}_{1}=\frac{2+\alpha-\Delta}{3}$. Once again, if $\Delta$ is sufficiently small, tying can increase welfare. Otherwise, tying decreases welfare.

\section{Proof of Proposition 6}

To derive the equilibrium prices under tying, note that firm 1's and firm 2's total profits are respectively given by

$$
\begin{gathered}
\widetilde{\Pi}_{1}\left(\widetilde{P}, n_{1}^{c}\left(\widetilde{P}, \widetilde{p}_{2}\right)\right)=(\widetilde{P}+\alpha) n_{1}^{c}+\underbrace{\left(\frac{\beta_{a} n_{1}^{c}}{2}\right)^{2}}_{\text {Profit from the App Side }} \\
\tilde{\pi}^{2}\left(\widetilde{p}_{2}, n_{2}^{c}\left(\widetilde{P}, \widetilde{p}_{2}\right)\right)=\widetilde{p}_{2} n_{2}^{c}+\left(\frac{\beta_{a} n_{2}^{c}}{2}\right)^{2}
\end{gathered}
$$

\footnotetext{
${ }^{54}$ We can also show that if $\Delta>1 / 7$, tying reduces welfare regardless of the value of $\alpha$.
} 
Firm 1's first-order condition for profit maximization is given by

$$
\begin{aligned}
\frac{\partial \widetilde{\Pi}_{1}}{\partial \widetilde{P}} & =n_{1}^{c}+\left[\widetilde{P}+\alpha+\frac{\left(\beta_{a}\right)^{2} n_{1}^{c}}{2}\right] \frac{\partial n_{1}^{c}}{\partial \widetilde{P}} \\
& =-\frac{1}{1-\beta_{c} \beta_{a}}\left[\widetilde{P}+\alpha-n_{1}^{c}\left(1-\beta_{c} \beta_{a}-\frac{\left(\beta_{a}\right)^{2}}{2}\right)\right]
\end{aligned}
$$

where $\frac{\partial n_{1}^{c}}{\partial \widetilde{P}}=-\frac{1}{1-\beta_{c} \beta_{a}}\left(=-\frac{\partial n_{2}^{c}}{\partial \widetilde{P}}\right)$. Using $\Psi \equiv 1-\beta_{c} \beta_{a}-\frac{\left(\beta_{a}\right)^{2}}{2}$, we can rewrite the expression above as

$$
\frac{\partial \widetilde{\Pi}_{1}}{\partial \widetilde{P}}=-\frac{1}{1-\beta_{c} \beta_{a}}\left[\widetilde{P}+\alpha-n_{1}^{c} \Psi\right] .
$$

If $\Psi<0$, we always have $\frac{\partial \widetilde{\Pi}^{1}}{\partial \widetilde{P}}<0$, implying that $\widetilde{P}=0$ is optimal in the interior equilibrium where $n_{2}^{c}>0$. In a tipping equilibrium with foreclosure where $n_{2}^{c}=0$, there is no market share to gain and hence it is not optimal to reduce the price further and we will have $\widetilde{P}=\widetilde{p}+(\eta-\Delta)$.

Similarly, firm 2's first-order condition for profit maximization is given by

$$
\begin{aligned}
\frac{\partial \widetilde{\pi}_{2}}{\widetilde{p}_{2}} & =n_{2}^{c}+\left[\widetilde{p}_{2}+\frac{\left(\beta_{a}\right)^{2} n_{2}^{c}}{2}\right] \frac{\partial n_{2}^{c}}{\widetilde{p}_{2}} \\
& =-\frac{1}{1-\beta_{c} \beta_{a}}\left[\widetilde{p}_{2}-n_{2}^{c} \Psi\right]
\end{aligned}
$$

where $\frac{\partial n_{2}^{c}}{\partial \widetilde{p}_{2}}=-\frac{1}{1-\beta_{c} \beta_{a}}$. Once again, if $\Psi<0$, we have $\frac{\partial \widetilde{\pi}_{2}}{\widetilde{p}_{2}}<0$, implying that $\widetilde{p}_{2}=0$ is optimal.

Note that the second-order derivatives for firm 1 and firm 2 are the same and given by:

$$
\frac{\partial^{2} \widetilde{\Pi}_{1}}{\partial \widetilde{P}^{2}}=\frac{\partial^{2} \widetilde{\pi}_{2}}{\partial \widetilde{p}_{2}^{2}}=-\frac{1}{1-\beta_{c} \beta_{a}}-\left[1-\frac{\left(\beta_{a}\right)^{2}}{2} \frac{1}{1-\beta_{c} \beta_{a}}\right] \frac{1}{1-\beta_{c} \beta_{a}} .
$$

They are negative if

$$
\left(\beta_{a}\right)^{2}<4\left(1-\beta_{c} \beta_{a}\right)
$$

which is equivalent to

$$
\beta_{c} \beta_{a}+\frac{1}{4}\left(\beta_{a}\right)^{2}<1
$$

We consider two cases depending on the magnitudes of intergroup externality para- 
meters (i.e., the sign of $\Psi$ ).

Case 1. $\Psi<0$ (i.e., $\beta_{c} \beta_{a}+\frac{\left(\beta_{a}\right)^{2}}{2}>1$ )

In this case, the equilibrium prices are $\widetilde{p}_{2}^{*}=0$ and $\widetilde{P}^{*}=\max \{0, \eta-\Delta\}$ as $\frac{\partial \widetilde{\pi}_{2}}{\widetilde{p}_{2}}<0$. We can have two types of equilibria depending on the relative magnitude of $\eta$ and $\Delta$ : a tipping equilibrium or an interior equilibrium. We have the following lemma that characterizes equilibrium in this case.

Lemma 7. Suppose that $\Psi<0$. Then, we have $\widetilde{p}_{2}^{*}=0$.

(i) If $\eta>\Delta$, we have a tipping equilibrium in which $n_{2}^{c *}=0$ and $\widetilde{P}^{*}>0$.

(ii) If $\eta<\Delta$, we have an interior equilibrium with $n_{2}^{c *}>0$ and both prices being driven down to zero $\left(\widetilde{P}^{*}=\widetilde{p}_{2}^{*}=0\right)$, where

$$
\begin{aligned}
& n_{2}^{c *}=\frac{\Delta-\eta}{\left(1-\beta_{c} \beta_{a}\right)}>0 ; \\
& n_{1}^{c *}=1-n_{2}^{c *}=\frac{1-(\Delta+\eta)}{\left(1-\beta_{c} \beta_{a}\right)}>0 .
\end{aligned}
$$

Case 2. $\Psi \geq 0$ (i.e., $\beta_{c} \beta_{a}+\frac{\left(\beta_{a}\right)^{2}}{2} \leq 1$ )

We also consider two types of equilibria under tying in this case: a tipping equilibrium and an interior equilibrium. Note that in this case (i.e., when $\Psi \geq 0$ ), the second-order condition is always satisfied in each firm's maximization problem.

Tipping Let us first analyze the possibility of a tipping equilibrium. In a tipping equilibrium with $n_{2}^{c *}=0$, we have the following first-order condition for firm 2 :

$$
\frac{\partial \widetilde{\pi}_{2}}{\widetilde{p}_{2}}=-\frac{\widetilde{p}_{2}}{1-\beta_{c} \beta_{a}} \leq 0
$$

Hence, $\widetilde{p}_{2}^{*}=0$. Then, the highest $\widetilde{P}$ consistent with tipping is $\widetilde{P}^{*}=\max \{0, \eta-\Delta\}$. At this price, firm 1 must have no incentive to deviate; the first-order derivative must be zero or negative.

If $\eta<\Delta$, the equilibrium prices in a tipping equilibrium need to be $\widetilde{P}^{*}=\widetilde{p}_{2}^{*}=0$. However, at these prices firm 2 has a strictly positive market share. We thus have a contradiction and there cannot be a tipping equilibrium if $\eta<\Delta$. 
If $\eta \geq \Delta$, then $\widetilde{P}^{*}=\eta-\Delta$ and the following condition must hold:

$$
\frac{\partial \widetilde{\Pi}_{1}}{\widetilde{P}}=-\frac{1}{1-\beta_{c} \beta_{a}}[\eta-\Delta+\alpha-\Psi] \leq 0,
$$

which is equivalent to

$$
\alpha \geq(\Delta-\eta)+\Psi
$$

Summarizing, we have:

Lemma 8. Suppose that $\Psi \geq 0$. There is a tipping equilibrium in which $\widetilde{P}^{*}=\eta-\Delta \geq$ $p^{*}=0$ if $\eta \geq \Delta$ and $\alpha \geq(\Delta-\eta)+\Psi$, where $\Psi=1-\beta_{c} \beta_{a}-\frac{\left(\beta_{a}\right)^{2}}{2}$.

Interior Equilibrium Let us look for an interior equilibrium (i.e., each firm has a positive market share): $0<n_{2}^{c *}<1$. For an interior equilibrium, firm 2's first-order condition for profit maximization is given by

$$
\widetilde{p}_{2}^{*}=n_{2}^{c *} \Psi>0
$$

However, $\widetilde{P}^{*}$ can be zero. From firm 1's first-order condition, we have:

$$
\widetilde{P}^{*}=\max \left\{0,-\alpha+n_{1}^{c *} \Psi\right\} .
$$

Consider the case of $\widetilde{P}^{*}=0$. Then, from the demand function and (5), we have

$$
n_{2}^{c *}=\frac{(\Delta-\eta)-n_{2}^{c *} \Psi}{\left(1-\beta_{c} \beta_{a}\right)}
$$

By collecting terms in $n_{2}^{c *}$, we have

$$
n_{2}^{c *}=\frac{\Delta-\eta}{\Psi+\left(1-\beta_{c} \beta_{a}\right)} .
$$

$\widetilde{P}^{*}=0$ is an equilibrium price for firm 1 if

$$
n_{1}^{c *} \Psi \leq \alpha
$$


which is equivalent to

$$
\left[1-\frac{\Delta-\eta}{\Psi+\left(1-\beta_{c} \beta_{a}\right)}\right] \Psi \leq \alpha
$$

If (6) is violated, then

$$
\widetilde{P}^{*}=-\alpha+n_{1}^{c *} \Psi>0
$$

Then,

$$
\widetilde{P}^{*}-\widetilde{p}_{2}^{*}=\left(1-2 n_{2}^{c *}\right) \Psi-\alpha .
$$

Putting this into the market share equation leads to

$$
n_{2}^{c *}\left(1-\beta_{c} \beta_{a}\right)=(\Delta-\eta)+\left(1-2 n_{2}^{c *}\right) \Psi-\alpha,
$$

which can be rewritten as

$$
n_{2}^{c *}\left[3 \Psi+\frac{\left(\beta_{a}\right)^{2}}{2}\right]=(\Delta-\eta)-\alpha+\Psi .
$$

Therefore,

$$
\begin{aligned}
n_{2}^{c *} & =\frac{(\Delta-\eta)-\alpha+\Psi}{3\left[\Psi+\frac{\left(\beta_{a}\right)^{2}}{6}\right]} \\
& =\frac{\frac{3}{2}\left[\Psi+\frac{\left(\beta_{a}\right)^{2}}{6}\right]-\frac{1}{2}+\Delta-\alpha}{3\left[\Psi+\frac{\left(\beta_{a}\right)^{2}}{6}\right]} \\
& =\frac{1}{2}-\frac{1+2 \alpha-2 \Delta}{6 \Psi+\left(\beta_{a}\right)^{2}}
\end{aligned}
$$

Hence, firm 1's market share is

$$
n_{1}^{c *}=1-n_{2}^{c *}=\frac{1}{2}+\frac{1+2 \alpha-2 \Delta}{6 \Psi+\left(\beta_{a}\right)^{2}} .
$$

Because we assume $\Psi=1-\beta_{c} \beta_{a}-\frac{\left(\beta_{a}\right)^{2}}{2}>0$, the denominator in the market share expression is strictly positive. Under the maintained assumption of $\Delta<1 / 2$, firm 1's market share is larger than $1 / 2$, which is the market size in the monopolized market $A$ without tying when it is one-sided (i.e., when $\alpha=0$ ). The market share for firm 1 increases with $\alpha$ and decreases with $\Delta$, as expected. The market share's response to $\alpha$ or 
$\Delta$ is greater as the intergroup externalities in market $B$ becomes more important (i.e., as $\beta_{c}$ or $\beta_{a}$ increases).

Firm 1's equilibrium price is

$$
\begin{aligned}
\widetilde{P}^{*} & =-\alpha+n_{1}^{c *} \Psi \geq 0 . \\
& =-\alpha+\frac{\Psi}{2}+\frac{(1+2 \alpha-2 \Delta) \Psi}{6 \Psi+\left(\beta_{a}\right)^{2}}
\end{aligned}
$$

We find

$$
\begin{aligned}
& \frac{\partial \widetilde{P}^{*}}{\partial \alpha}=-1+\frac{2 \Psi}{6 \Psi+\frac{\left(\beta_{a}\right)^{2}}{2}} \\
& =-\frac{4 \Psi+\left(\beta_{a}\right)^{2}}{6 \Psi+\left(\beta_{a}\right)^{2}}<0 . \\
& \frac{\partial \widetilde{P}^{*}}{\partial \Delta}<0 \\
& \frac{\partial \widetilde{P}^{*}}{\partial \beta_{c}}=n_{1}^{c *} \frac{\partial \Psi}{\partial \beta_{c}}+\Psi \cdot \frac{\partial n_{1}^{c *}}{\partial \beta_{c}} \\
& =-\beta_{a}\left[\frac{1}{2}+\frac{1+2 \alpha-2 \Delta}{6 \Psi+\left(\beta_{a}\right)^{2}}\right]+\Psi \cdot \beta_{a} \frac{1+2 \alpha-2 \Delta}{6\left[\Psi+\frac{\left(\beta_{a}\right)^{2}}{6}\right]^{2}} \\
& =-\beta_{a}\left[\frac{1}{2}+\frac{1+2 \alpha-2 \Delta}{6\left[\Psi+\frac{\left(\beta_{a}\right)^{2}}{6}\right]}\left[1-\frac{\Psi}{\left.\Psi+\frac{\left(\beta_{a}\right)^{2}}{6}\right]}\right]<0\right. \text {. }
\end{aligned}
$$

Firm 2's equilibrium price is

$$
\begin{aligned}
\widetilde{p}_{2}^{*} & =n_{2}^{c *} \Psi \\
& =\left(\frac{1}{2}-\frac{1+2 \alpha-2 \Delta}{6 \Psi+\left(\beta_{a}\right)^{2}}\right) \Psi .
\end{aligned}
$$

For a given market share, $\beta_{c} \beta_{a}>0$ induces firm 2 to charge a lower price to consumers for product $B$ than when $\beta_{c} \beta_{a}=0$. In addition, as long as $1+2 \alpha-2 \Delta>0$, firm 2's market share is smaller when $\beta_{c} \beta_{a}>0$ than when $\beta_{c} \beta_{a}=0$. Hence, both factors would induce firm 2 to become more aggressive.

Summarizing, we have: 
Lemma 9. Suppose that $\Psi \geq 0$ and the conditions for the tipping equilibrium in Lemma 8 are not met. Then, there is an interior equilibrium such that

(i) if (6) is satisfied, $\widetilde{P}^{*}=0, \widetilde{p}_{2}^{*}=n_{2}^{c *} \Psi>0$ and

$$
n_{2}^{c *}=\frac{\Delta-\eta}{2 \Psi+\frac{\left(\beta_{a}\right)^{2}}{2}} .
$$

(ii) if (6) is violated, $\widetilde{P}^{*}=-\alpha+\left(1-n_{2}^{c *}\right) \Psi>0, \widetilde{p}_{2}^{*}=n_{2}^{c *} \Psi>0$ and

$$
n_{2}^{c *}=\frac{1}{2}-\frac{1+2 \alpha-2 \Delta}{6 \Psi+\left(\beta_{a}\right)^{2}}
$$

All the results in lemmas 7-9 we derived under different parameter configurations can be summarized as in Proposition 6. 